\title{
The Interaction of Activated Integrin Lymphocyte Function-associated Antigen 1 with Ligand Intercellular Adhesion Molecule 1 Induces Activation and Redistribution of Focal Adhesion Kinase and Proline-rich Tyrosine Kinase 2 in T Lymphocytes
}

\author{
José Luis Rodríguez-Fernández, ${ }^{*}$ Manuel Gómez, ${ }^{+}$Alfonso Luque, ${ }^{*}$ Nancy \\ Hogg, ${ }^{\ddagger}$ Francisco Sánchez-Madrid, ${ }^{+}$and Carlos Cabañas ${ }^{*}$
}

*Departamento de Bioquímica y Biología Molecular, Facultad de Medicina, Universidad Complutense, 28040 Madrid, Spain; 'Servicio de Inmunología, Hospital de la Princesa, 28006 Madrid, Spain; and ‡Leukocyte Adhesion Laboratory, Imperial Cancer Research Fund, London WC2A 3PX, United Kingdom

Submitted August 3, 1998; Accepted March 31, 1999

Monitoring Editor: Joan Brugge

\begin{abstract}
Integrin receptors play a central role in the biology of lymphocytes, mediating crucial functional aspects of these cells, including adhesion, activation, polarization, migration, and signaling. Here we report that induction of activation of the $\beta 2$-integrin lymphocyte function-associated antigen 1 (LFA-1) in T lymphocytes with divalent cations, phorbol esters, or stimulatory antibodies is followed by a dramatic polarization, resulting in a characteristic elongated morphology of the cells and the arrest of migrating lymphoblasts. This cellular polarization was prevented by treatment of cells with the specific tyrosine kinase inhibitor genistein. Furthermore, the interaction of the activated integrin LFA-1 with its ligand intercellular adhesion molecule 1 induced the activation of the cytoplasmic tyrosine kinases focal adhesion kinase (FAK) and proline-rich tyrosine kinase 2 (PYK-2). FAK activation reached a maximum after 45 min of stimulation; in contrast, PYK-2 activation peaked at $30 \mathrm{~min}$, declining after $60 \mathrm{~min}$. Upon polarization of lymphoblasts, FAK and PYK-2 redistributed from a diffuse localization in the cytoplasm to a region close to the microtubule-organizing center in these cells. FAK and PYK-2 activation was blocked when lymphoblasts were pretreated with actin and tubulin cytoskeleton-interfering agents, indicating its cytoskeletal dependence. Our results demonstrate that interaction of the $\beta 2$-integrin LFA- 1 with its ligand intercellular adhesion molecule 1 induces remodeling of T lymphocyte morphology and activation and redistribution of the cytoplasmic tyrosine kinases FAK and PYK-2.
\end{abstract}

\section{INTRODUCTION}

Integrins are heterodimeric cell surface proteins that function in cell adhesion, cytoskeleton anchorage, and the transduction of cellular stimuli into cytoplasmic signals (Clark and Brugge, 1995; Schwartz et al., 1995).

\footnotetext{
§Corresponding author. E-mail address: cacabagu@eucmax. sim.ucm.es.
}

The $\beta 2$-integrin lymphocyte function-associated antigen 1 (LFA-1; CD11a/CD18) is selectively expressed on leukocytes and mediates important adhesive phenomena of these cells through interaction with its ligands intercellular adhesion molecule 1 (ICAM-1; CD54), ICAM-2 (CD102), and ICAM-3 (CD50). The resting leukocytes, which circulate in the bloodstream, express an inactive form of LFA-1 that is functionally unable to mediate interactions with ICAMs. Induction 
of leukocyte activation through different cell surface receptors, including the T cell receptor-CD3 complex and receptors for cytokines, results in the generation of intracellular signals that lead to activation of LFA-1 molecules. This "inside-out" mechanism of LFA-1 activation brings about a change in the conformation of the extracellular region of the integrin, which is functionally reflected by the ability of the cells to adhere to LFA-1 ligands. Activation of LFA-1 molecules can also be induced directly from outside the cells by altering the extracellular divalent cation conditions, i.e. by addition of micromolar concentrations of $\mathrm{Mn}^{2+}$ or by the presence of millimolar levels of $\mathrm{Mg}^{2+}$ when $\mathrm{Ca}^{2+}$ is removed with EGTA (Dransfield et al., 1992a). Direct activation of LFA-1 from outside the cells can also be achieved with specific "activating" or "stimulating" $\mathrm{mAbs}$. These types of antibodies recognize and bind to the $\alpha$ or the $\beta$ subunits of LFA-1, altering the conformation of the integrin to a state of increased affinity for its ligands. Activating LFA-1 antibodies include NKIL16, which is specific for the $\alpha$ subunit or CD11a, and KIM-127 and KIM-185, which are directed to the common $\beta 2$ subunit CD18 (van Kooyk et al., 1991; Ortlepp et al., 1995; Stephens et al., 1995). Phorbol esters such as phorbol-12,13-dibutyrate (PDBu), which are potent and sustained activators of PKC, have also been used extensively as another means of inducing LFA-1-mediated adhesion to ICAMs (Rothlein and Springer, 1986; Stewart et al., 1996).

Upon ligand engagement of LFA-1, a variety of intracellular signals are generated in T lymphocytes, including phosphorylation of phospholipase $\mathrm{C} \gamma 1$, phospholipid hydrolysis, activation of different isoenzymes of PKC, mobilization of intracellular $\mathrm{Ca}^{2+}$, and activation of tyrosine kinases (Wacholtz et al., 1989; Kanner et al., 1993; Arroyo et al., 1994; Lub et al., 1995). The focal adhesion kinase (FAK) is a nonreceptor protein-tyrosine kinase that colocalizes to cellular focal adhesions with integrins (Hanks et al., 1992; Schaller et al., 1992). FAK, one of the major substrates for integrin-dependent tyrosine phosphorylation, is considered an important element in an integrin-regulated pathway (Clark and Brugge, 1995; Richardson and Parsons, 1995; Otey, 1996; Hanks and Polte, 1997). FAK is tyrosine phosphorylated upon stimulation of $\beta 1$-integrins in fibroblasts, epidermal carcinoma cells, mast cells, and T lymphocytes; upon engagement of $\beta 3$-integrin in platelets and upon transfection of human fibroblasts with chimeric receptors containing either the $\beta 1-, \beta 3-$, or $\beta 5$-integrin intracellular domain (Kornberg et al., 1991; Guan and Shalloway, 1992; Lipfert et al., 1992; Hamawy et al., 1993; Akiyama et al., 1994; Matsumoto et al., 1994; Shattil et al., 1994; Maguire et al., 1995). Concomitant with tyrosine phosphorylation, FAK becomes enzymatically active (Guan and Shalloway, 1992; Lipfert et al., 1992; Otey, 1996). A variety of studies, including the characterization of cells derived from FAK $(-/-)$ embryos, suggests that FAK may be involved in the regulation of cell spreading and motility (Gates et al., 1994; Akasaka et al., 1995; Ilic et al., 1995; Cary et al., 1996; Gilmore and Romer, 1996; Richardson and Parsons, 1996).

A second member of the FAK nonreceptor tyrosine kinase family, known as proline-rich tyrosine kinase 2 (PYK-2), and also called related adhesion focal tyrosine kinase, cell adhesion kinase $\beta$, calcium-dependent tyrosine kinase, or FAK2, has been described (Avraham et al., 1995; Earp et al., 1995; Lev et al., 1995; Sasaki et al., 1995; Herzog et al., 1996). PYK-2 is less evenly expressed in tissues and restricted to a lower number of cell types compared with FAK; however, the expression is high in cells of neural, epithelial, or hematopoetic origin (Avraham et al., 1995; Lev et al., 1995; Yu et al., 1996). PYK-2 shares significant homology with FAK $(60 \%$ identity in the central catalytic domain and $40 \%$ identity in both $\mathrm{C}$ and $\mathrm{N}$ termini) and, like FAK, does not contain Src homology 2 (SH2) or SH3 domains but contains several sites for binding of SH2- and SH3-containing signaling proteins. Regulation of PYK-2 localization and tyrosine phosphorylation seems to be cell type and integrin specific. PYK-2 localizes to focal contacts and displays a $\beta 1$-integrin-dependent phosphorylation in natural killer cells, B lymphocytes, megakaryocytes and transfected COS cells and exhibits a $\beta 3$-dependent tyrosine phosphorylation in T lymphocytes (Li et al., 1996; Astier et al., 1997; Gismondi et al., 1997; Ma et al., 1997). However, PYK-2 was localized to intercellular junctions and was not tyrosine phosphorylated upon adhesion of transfected 3Y1 fibroblasts on fibronectin or integrin ligation during platelet aggregation (Sasaki et al., 1995; Raja et al., 1997). It has been suggested that the differences in localization and tyrosine phosphorylation of FAK and PYK-2 may be due to differences in the sequences of the $C$ termini of FAK and PYK-2 (Zheng et al., 1998). Several studies suggest that PYK-2 may be involved in the control of apoptosis and the regulation of ion channels in neuronal cells (Lev et al., 1995; Xiong and Parsons, 1997).

After activation and autophosphorylation of FAK and PYK-2, these enzymes may serve as recruiting molecules for various signaling and cytoskeletal proteins, including the tyrosine kinases Src and Fyn, and the focal contact proteins paxillin and $\mathrm{p} 130^{\mathrm{Cas}}$, which are also potential targets for FAK and PYK-2 phosphorylation (Richardson and Parsons, 1995; Dikic et al., 1996; Astier et al., 1997; Ganju et al., 1997; Gismondi et al., 1997; Hanks and Polte, 1997; Hiregowdara et al., 1997; Ohba et al., 1998; Schlaepfer and Hunter, 1998). Therefore, integrin signaling, involving the activation of FAK and PYK-2, has also been suggested to modulate the reorganization of the actin cytoskeleton and to regulate changes in cell morphology. Polarization is a key feature in the biology of T cells (Wilkinson and 
Higgins, 1987; del Pozo et al., 1996; Sánchez-Madrid and del Pozo, 1999). Lymphocytes acquire a polarized phenotype after activation, upon interaction with antigen-presenting cells (APCs) and during chemokinedirected transendothelial migration. The leukocyte integrin LFA-1 plays a key role in these crucial events of immune and inflammatory responses (Springer, 1990; Dransfield et al., 1992a). Furthermore, cell polarization in lymphocytes involves a reorganization of the cytoskeleton, including polymerization and redistribution of actin and reorientation of the microtubuleorganizing center (MTOC) toward the opposing cell (Singer, 1992; Dustin et al., 1997; Lowin-Kropf et al., 1998).

In this study we have analyzed some of the morphological and functional changes that occur in $\mathrm{T}$ lymphocytes after induction of activation of the integrin LFA-1 and its interaction with its ligand ICAM-1. We demonstrate that functional activation of LFA-1 brings about dramatic changes in the morphology and polarization of these cells, converting them into a nonmotile phenotype. We also demonstrate, for the first time, that concomitantly with these changes, the two homologous cytoplasmic tyrosine kinases FAK and PYK-2 become activated and redistributed intracellularly, colocalizing in the polarized $\mathrm{T}$ cell with the MTOC.

\section{MATERIALS AND METHODS}

\section{Cells}

Human $\mathrm{T}$ lymphoblasts were prepared from peripheral blood mononuclear cells by treatment with $0.5 \%$ phytohemagglutinin for 48 h. Cells were washed and cultured in RPMI 1640 (Flow Laboratories, Irvine, Scotland) containing 10\% FCS (Flow Laboratories) and interleukin $2(20 \mathrm{U} / \mathrm{ml})$. T lymphoblasts cultured by 7-12 d were typically used in all experiments (Dransfield et al., 1992b; Luque et al., 1996; Stewart et al., 1996).

\section{Antibodies and Reagents}

A dimeric form of an ICAM-1-Fc chimeric protein consisting of the five domains of ICAM-1 fused to the Fc fragment of human IgG1 was prepared as previously described (Berendt et al., 1992). The LFA-1-stimulatory mAb KIM-127, which is specific for the $\beta 2$-integrin subunit (Ortlepp et al., 1995; Stephens et al., 1995) was a generous gift of Dr. Martyn Robinson (Celltech, Slough, United Kingdom). FAK antipeptide polyclonal antibodies C-20 and A-17 and PYK-2 antipeptide polyclonal antibodies C-19 and N-19 were from Santa Cruz Biotechnology (Santa Cruz, CA). The anti-FAK C-20 and A-17 polyclonal antibodies were raised against peptides corresponding to amino acids 1033-1052 mapping at the $C$ terminus and amino acids 2-18 mapping at the $\mathrm{N}$ termini of human FAK, respectively. The anti-PYK-2 polyclonal antibodies C-19 and N-19 were raised against peptides corresponding to amino acids 990-1009, mapping at the $\mathrm{C}$ terminus, and amino acids 2-20, mapping at the amino terminus, of human PYK-2, respectively. The anti-Tyr(P) PY20 and the anti-FAK a-FAK mAbs were from Transduction Laboratories (Lexington, $\mathrm{KY}$ ). The $\mathrm{mAb}$ a-FAK recognizes an epitope in the kinase domain of FAK, corresponding to amino acids 354-533 of the chicken protein. The anti-FAK mAb $2 \mathrm{~A} 7$ was from Upstate Biotechnology (Lake Placid, NY). The $2 \mathrm{~A} 7 \mathrm{mAb}$ recognizes an epitope in the C domain of FAK (Schaller et al., 1993). The anti$\operatorname{Tyr}(\mathrm{P}) \mathrm{mAb}$ clone PY72 was obtained from the Hybridoma Development Unit, Imperial Cancer Research Fund. [ $\gamma^{-32}$ P]ATP $(4000$ $\mathrm{Ci} / \mathrm{mmol})$ and $\mathrm{L}-\left[{ }^{35} \mathrm{~S}\right]$ methionine $(400 \mathrm{Ci} / \mathrm{mmol})$ were from $\mathrm{ICN}$ Biochemicals (Costa Mesa, CA). Phytohemagglutinin, BSA, poly Glu:Tyr (4:1), poly-L-lysine, cytochalasin D, colchicine, the anti- $\alpha$ tubulin $\mathrm{mAb}$, and the FITC- and TRITC-conjugated secondary antibodies were all obtained from Sigma (St. Louis, MO). Protein A-agarose and Protein G-agarose were from Boehringer Mannheim (Mannheim, Germany). ECL reagents were from Amersham (Buckinghamshire, United Kingdom). Tyrosine kinases inhibitor genistein was from Calbiochem-Novabiochem (Nottingham, United Kingdom). Interleukin 2 was from Eurocetus (Amsterdam, The Netherlands). Taxol was a kind gift from Dr. J.M. Andreu (Centro de Investigaciones Biológicas, Consejo Superior de Investigaciones Científicas, Madrid, Spain). All other reagents used were of the purest grade available.

\section{Cell Attachment Assays}

Cell adhesion assays were essentially performed as described elsewhere (Dransfield et al., 1992b; Luque et al., 1996). Briefly, 96-well flat-bottom plates were precoated overnight at $4^{\circ} \mathrm{C}$ with $6 \mu \mathrm{g} / \mathrm{ml}$ ICAM-1-Fc in adhesion buffer $(20 \mathrm{mM}$ Tris- $\mathrm{HCl}$ and $150 \mathrm{mM} \mathrm{NaCl}$, $\mathrm{pH}$ 8.2), blocked with $1 \%$ BSA in adhesion buffer for $1 \mathrm{~h}$ at room temperature, and then washed twice with RPMI 1640. In control nonspecific adhesion experiments, wells were precoated overnight at $4^{\circ} \mathrm{C}$ with $20 \mu \mathrm{g} / \mathrm{ml}$ poly-L-lysine in water. T lymphoblasts $(3 \times$ $10^{5}$ cells per well) were then added to the wells containing or not the relevant stimuli for LFA-1 activation. When $\mathrm{Mg}^{2+}$-EGTA was used to stimulate LFA-1, cells were washed in HEPES- $\mathrm{NaCl}$ buffer (20 $\mathrm{mM}$ HEPES, $150 \mathrm{mM} \mathrm{NaCl}$, and $2 \mathrm{mg} / \mathrm{ml}$ glucose, $\mathrm{pH}$ 7.4) instead of RPMI 1640 medium. After $20 \mathrm{~min}$ on ice, incubation of plates continued for $60 \mathrm{~min}$ at $37^{\circ} \mathrm{C}$. Plates were then washed gently four times with prewarmed RPMI 1640, and bound cells were quantitated by measuring the absorbance of wells at $540 \mathrm{~nm}$ after fixation and staining with $0.5 \%$ crystal violet in $20 \%$ methanol.

\section{Digital Confocal Microscopy}

For immunofluorescence analysis, round glass coverslips (13 mm diameter) were precoated with recombinant ICAM-1Fc protein and blocked with $1 \%$ BSA as indicated above. T lymphoblasts were washed twice in HEPES- $\mathrm{NaCl}$ buffer and allowed to adhere to the ICAM-1Fc-coated coverslips for $60 \mathrm{~min}$ at $37^{\circ} \mathrm{C}$. After two washes in PBS, adherent cells were fixed in $3.7 \%$ formaldehyde in PBS for 10 $\mathrm{min}$ at room temperature and then permeabilized in $0.1 \%$ Triton X-100 in PBS and 0.5\% BSA. Cells were then incubated for $45 \mathrm{~min}$ with rabbit anti-FAK (C-20 or A-17) or goat anti-PYK-2 (C-19 or $\mathrm{N}-19)$ polyclonal antibodies. Cells were then extensively washed in PBS and 0.5\% BSA and incubated for $60 \mathrm{~min}$ with the corresponding anti-goat or anti-rabbit FITC-conjugated secondary antibody. In some experiments, the samples were washed again with PBS, double stained with the anti- $\alpha$-tubulin $\mathrm{mAb}$ for $60 \mathrm{~min}$, and washed in PBS and $0.5 \%$ BSA, followed by an incubation for 60 min with an anti-mouse TRITC-conjugated secondary antibody. In the experiments in which actin was stained, cells were fixed as above and then treated with TRITC-conjugated phalloidin in PBS and 0.5\% BSA for $20 \mathrm{~min}$ and washed extensively in PBS. Before mounting the samples for fluorescence microscopy, they were washed again with PBS and distilled water. Confocal microscopy was performed using a MRC-1000 confocal laser scanning system (Bio-Rad, Watford, United Kingdom) connected to a Nikon (Tokyo, Japan) Diaphot 200 inverted microscope. Images of 20 serial vertical cellular sections were acquired every $0.5 \mu \mathrm{m}$ with the Bio-Rad COMOS graphical user interface and software. 


\section{Quantitative Time-Lapse Video Microscopy of T Lymphoblast Motility}

Plastic dishes ( $35 \mathrm{~mm}$ ) were precoated with recombinant ICAM-1FC protein and blocked with BSA as indicated above. T lymphoblasts were plated immediately before video recording in RPMI 1640 medium supplemented with 1\% FCS in the presence or absence of the relevant stimuli for LFA-1 activation. Time-lapse video films of cells were generated as a sequence of individual digital images ("frames") that were obtained every $10 \mathrm{~s}$ for $2.30 \mathrm{~h}$ in an Zeiss (Thornwood, NY) Axiovert 135 video microscope using the IP-Lab Spectrum software (Signal Analytics, Vienna, VA). The cellular random migration tracks, distances, and average speeds of individual cells for each experimental condition were obtained using the Cell Tracking software extension for IP-Lab Spectrum developed by Tim Hutton (Confocal Microscopy and Digital Image Unit, Imperial Cancer Research Fund).

\section{Immunoprecipitation}

T lymphoblasts $\left(100 \times 10^{6}\right.$ or $2.5 \times 10^{6}$ cells to immunoprecipitate FAK or PYK-2, respectively, unless otherwise stated) were washed twice with RPMI 1640, plated on dishes coated with either BSA or ICAM-1, and, after $15 \mathrm{~min}$ on ice, stimulated with $10 \mu \mathrm{g} / \mathrm{ml} \mathrm{mAb}$ KIM-127 for $60 \mathrm{~min}$. The stimulation was terminated by solubilizing the cells in $1 \mathrm{ml}$ of ice-cold lysis buffer (10 mM Tris-HCl, pH 7.65, 5 $\mathrm{mM}$ EDTA, $50 \mathrm{mM} \mathrm{NaCl}, 30 \mathrm{mM}$ sodium pyrophosphate, $50 \mathrm{mM}$ $\mathrm{NaF}, 2 \mathrm{mM}$ sodium orthovanadate, $1 \%$ Triton X-100, $50 \mu \mathrm{g} / \mathrm{ml}$ aprotinin, $50 \mu \mathrm{g} / \mathrm{ml}$ leupeptin, $5 \mu \mathrm{g} / \mathrm{ml}$ pepstatin, and $1 \mathrm{mM}$ PMSF). Lysates were clarified by centrifugation at $14,000 \mathrm{rpm}$ for 10 $\mathrm{min}$, and the pellets were discarded. After centrifugation, supernatants were transferred to fresh tubes, and proteins were immunoprecipitated at $4^{\circ} \mathrm{C}$ overnight with either protein A-agarose-linked rabbit polyclonal anti-FAK antibodies (C-20 or A-17) or protein G-agarose-linked mAbs directed against FAK (2A7 or a-FAK mAbs) or against $\operatorname{Tyr}(\mathrm{P})$ proteins (PY20 and PY72 mAbs) or protein Gagarose-linked goat polyclonal anti-PYK-2 antibody (C-19). Immunoprecipitates were washed three times with lysis buffer and either used for in vitro kinase reactions (see below) or extracted in $2 \times$ SDS-PAGE sample buffer $(200 \mathrm{mM}$ Tris- $\mathrm{HCl}, \mathrm{pH} 6.8,0.1 \mathrm{mM}$ sodium orthovanadate, $1 \mathrm{mM}$ EDTA, 6\% SDS, $2 \mathrm{mM}$ EDTA, $4 \%$ 2-mercaptoethanol, and $10 \%$ glycerol), by boiling $5 \mathrm{~min}$, fractionated by one-dimensional SDS PAGE, and further analyzed as described in RESULTS and figure legends.

\section{In Vitro Kinase Reactions}

Reactions were performed as described (Rodríguez-Fernández and Rozengurt, 1996, 1998). Briefly, immunoprecipitates were washed and pelleted (2500 rpm $10 \mathrm{~min}$ in the cold) three times in lysis buffer and twice with kinase buffer (20 mM HEPES and $3 \mathrm{mM} \mathrm{MnCl}_{2}, \mathrm{pH}$ 7.35). Pellets were dissolved in $40 \mu \mathrm{l}$ of kinase buffer, and reactions were started by adding $10 \mu \mathrm{Ci}$ of $\left[\gamma^{-32} \mathrm{P}\right] \mathrm{ATP}$. The reactions were carried out at $30^{\circ} \mathrm{C}$ for $15 \mathrm{~min}$ and were stopped on ice by adding 10 $\mathrm{mM}$ EDTA. After the in vitro kinase reactions, the pellet were washed in lysis buffer containing $10 \mathrm{mM}$ EDTA, extracted for $5 \mathrm{~min}$ at $95^{\circ} \mathrm{C}$ in $2 \times$ SDS-PAGE sample buffer, and analyzed by SDSPAGE. In some experiments poly-Glu-Tyr $(4: 1 ; 40 \mu \mathrm{g})$ was added to the immunocomplexes. The incorporation of ${ }^{32} \mathrm{P}$ label into poly-GluTyr (4:1) was stopped by removing the supernatant from the agarose beads and adding $2 \times$ SDS-PAGE sample buffer. Samples were then analyzed by SDS-PAGE and autoradiography. After fixing and drying of the gels, autoradiography was performed at $-80^{\circ} \mathrm{C}$. Autoradiograms were analyzed using an Agfa (Mortsel, Belgium) Studio Scan IIsi scanner, and bands were quantified using the Bio-Rad Molecular Analyst software.

\section{Western Blotting}

Cell lysis and immunoprecipitations were performed as described above. After SDS-PAGE, proteins were transferred to Immobilon membranes (Millipore, Bedford, MA) using a Bio-Rad SD Transblot. Membranes were blocked using 3\% nonfat dried milk in PBS, $\mathrm{pH}$ 7.2 , and incubated for $2 \mathrm{~h}$ at $22^{\circ} \mathrm{C}$ with the polyclonal antibodies anti-PYK-2 (C-19 or N-19), diluted 1:500 in PBS containing 3\% nonfat dried milk. After incubating membranes with HRP-conjugated secondary antibodies, immunoreactive bands were visualized using ECL reagents.

\section{Metabolic Labeling and Autoradiography}

Cells were labeled overnight with $\mathrm{L}^{35} \mathrm{~S}$ ] methionine at $100 \mu \mathrm{Ci} / \mathrm{ml}$ in methionine-free RPMI 1640 containing 5\% FCS, as described previously (Rodríguez-Fernández et al., 1992). Labeled proteins were used to immunoprecipitate FAK with the C-20 antibody. After immunoprecipitation and SDS-PAGE, the gels were soaked in DMSO twice, for 30 min periods, followed by treatment with $19 \%$ 2,5-diphenyloxazole (PPO) in DMSO for $2 \mathrm{~h}$. The DMSO-PPO was removed, and the gels were thoroughly washed in water. Gels were dried in a heated gel drier under vacuum and exposed to x-ray films.

\section{RESULTS}

\section{Morphological Changes in T Lymphoblasts after Induction of Activation of Integrin LFA-1}

In the absence of stimulation the majority of $\mathrm{T}$ lymphoblasts grow in suspension and remain as individual cells displaying a rounded appearance. Despite the high expression of both the integrin LFA-1 and its ligand ICAM-1 on the surface of these activated T cells, they do not form large intercellular aggregates, indicating that LFA- 1 is in an inactive state unable to mediate ligand interactions. When unstimulated $\mathrm{T}$ lymphoblasts are allowed to adhere to immobilized ligand ICAM-1, only a relatively low percentage of these cells are able to attach (Figure 1A, CONTROL). Induction of activation of LFA-1 molecules on T cells using activating $\mathrm{mAb} \mathrm{KIM}-127, \mathrm{Mg}^{2+}$-EGTA, or the phorbol ester PDBu results in an important increase in the percentage of cells adhering to ICAM-1 (Figure 1A). Interestingly, this augmented adhesion is accompanied by profound changes in the morphology of the adherent $T$ cells. The lymphoblasts changed from their round and moderately spread morphology to an elongated and highly spread phenotype, in which a cell body and a long, and generally unique, cell projection were clearly distinguishable (Figure 1B, ICAM-1). Staining of polymerized actin revealed that after $1 \mathrm{~h}$ of adhesion to ICAM-1, actin was redistributed and organized in a thin rim around the nucleus of the cell and, more importantly, in the long cytoplasmic projection (Figure 1B, ICAM-1). Cells plated on poly-Llysine, both unstimulated and stimulated with $\mathrm{mAb}$ KIM-127, attached and spread onto the dishes but did not exhibit any important change in their morphology (Figure 1B, PLL). These adhesion experiments under static conditions, together with the staining of actin in fixed cells, demonstrate that activation of LFA-1 induces important changes in the adhesion and morphology of T lymphocytes. 

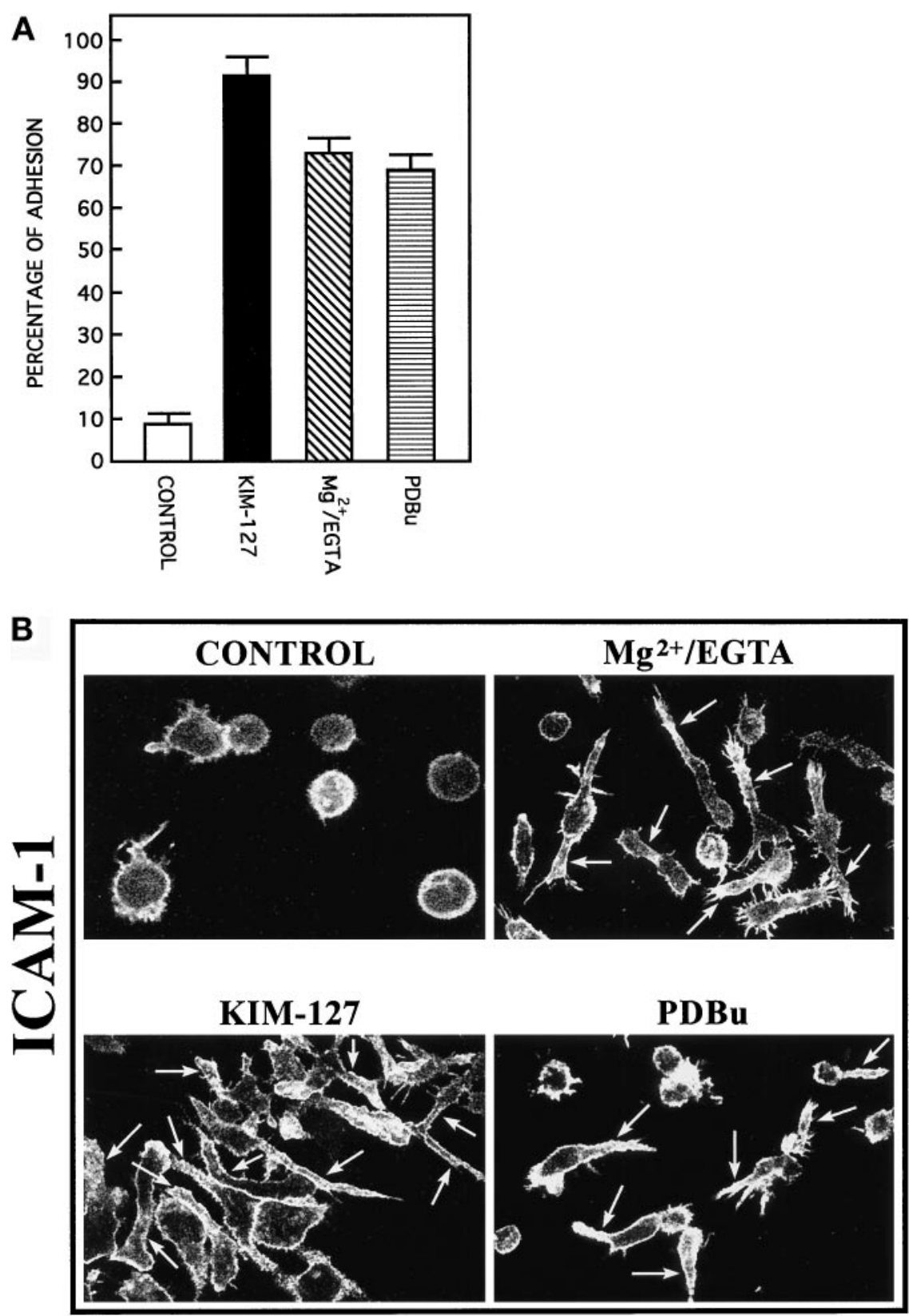

Figure 1. Agents that activate LFA-1 integrin cause an increment in adhesion and polarization of lymphoblasts. (A) T lymphoblasts plated on ICAM-1-Fc-coated plastic dishes were allowed to adhere for $60 \mathrm{~min}$ in the absence (CONTROL) or the presence of different of LFA-1-activating agents: 10 $\mu \mathrm{g} / \mathrm{ml} \mathrm{mAb}$ KIM-127 (KIM-127), $10 \mathrm{mM}$ $\mathrm{Mg}^{2+}$ plus $1 \mathrm{mM}$ EGTA $\left(\mathrm{Mg}^{2+} /\right.$ EGTA), and $50 \mathrm{nM}$ PDBu. Cell adhesion assays were carried out as specified in MATERIALS AND METHODS. The results are the mean \pm SEM of four independent experiments. (B) T lymphoblasts were plated either on ICAM-Fccoated dishes (ICAM-1) or on poly-L-lysinecoated dishes (PLL) and stimulated as indicated above. The cells were fixed, permeabilized, and stained with Texas Red-conjugated phalloidin. Immunofluorescence was analyzed by confocal laser microscopy as described in MATERIALS AND METHODS. Arrows indicate the position of the cellular extensions in representative polarized cells.

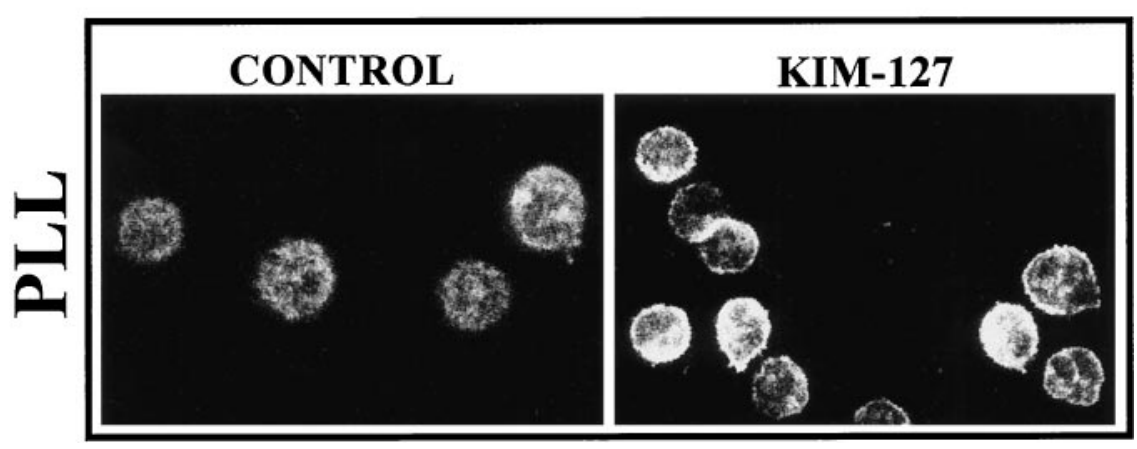




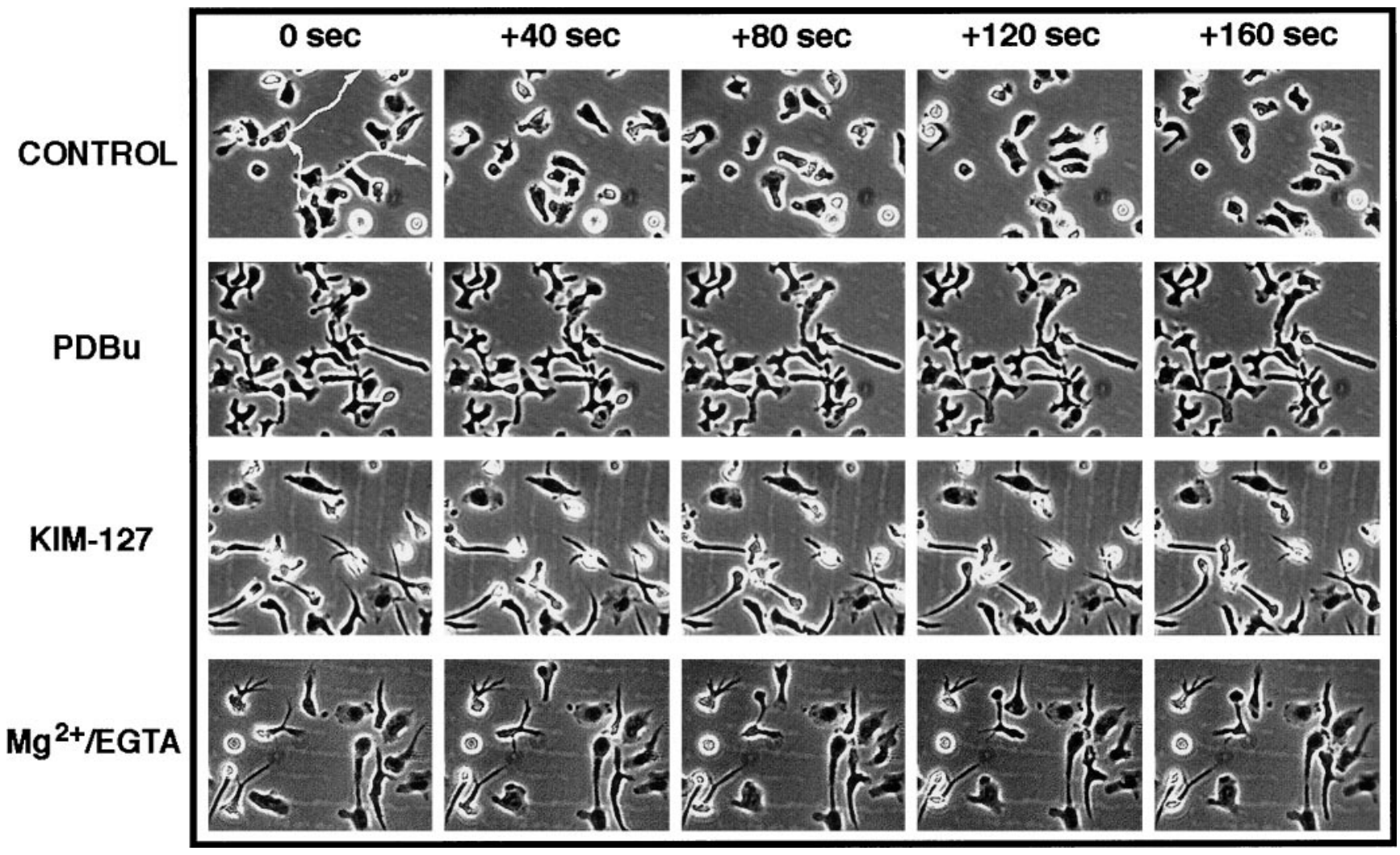

Figure 2. Lymphoblasts acquire a nonmotile phenotype after activation of integrin LFA-1. Lymphoblasts were allowed to bind on ICAM-1-Fc-coated dishes and stimulated for $45 \mathrm{~min}$ with saline solution (CONTROL), $50 \mathrm{nM} \mathrm{PDBu}, 10 \mu \mathrm{g} / \mathrm{ml} \mathrm{mAb}$ KIM-127, or $10 \mathrm{mM}$ $\mathrm{Mg}^{2+}$ plus $1 \mathrm{mM}$ EGTA $\left(\mathrm{Mg}^{2+} /\right.$ EGTA) before filming. The movement of the lymphoblasts was recorded by time-lapse video microscopy for $0,40,80,120$, and $160 \mathrm{~s}$. The trajectories of individual cells were analyzed, and representative migration tracks are shown.

Kinetics of Morphological Changes and Effects on $T$ Cell Motility of the Activation of LFA-1 Integrin

We used time-lapse digital video microscopy to investigate in detail the kinetics of the morphological changes and the effects that these changes had on the motility of lymphocytes after induction of activation of the LFA-1 molecules. The kinetics of induction of morphological changes was very similar for the three different protocols of activation of LFA-1 used $\left(\mathrm{Mg}^{2+}\right.$ EGTA, activating mAb KIM127, and PDBu). The changes in cell morphology were already evident after $20 \mathrm{~min}$, and after $60 \mathrm{~min}$ of induction of LFA-1 activation, $>90 \%$ of $\mathrm{T}$ lymphoblasts displayed the characteristic morphological features shown in Figure 1B.

The experiments of video microscopy also revealed that induction of activation of LFA-1 on T lymphoblasts adhering to ICAM-1 results in a switch from a highly motile to a nonmotile phenotype (Figure 2). In the arrested lymphoblasts, the cellular projection extending from the body of the cell seems to be firmly anchored to the substrate, and only the cell body of the lymphoblasts exhibited some lateral motility. Furthermore, quantitation of the distances traveled by the cell bodies of individual lymphoblasts and their average speeds in micrometers per hour confirmed that induction of activation of LFA-1 with PDBu, mAb KIM127, or $\mathrm{Mg}^{2+}$-EGTA results in a striking 13-fold reduction in the motility of these cells, decreasing from almost $1700 \mu \mathrm{m} / \mathrm{h}$ (nonactivated) to $130 \mu \mathrm{m} / \mathrm{h}$ (activated LFA-1) (Table 1).

\section{Inhibition of Morphological Changes Induced by Stimulation of LFA-1 by the Tyrosine Kinase Inhibitor Genistein}

To investigate whether tyrosine phosphorylation is required for the observed changes in morphology and level of adhesion of $\mathrm{T}$ lymphoblasts induced through activation of LFA-1, we tested the effect of the specific tyrosine kinase inhibitor genistein (Akiyama et al., 1987). As observed in Figure 3A, the addition of genistein at $30 \mu \mathrm{M}$ to cells plated on dishes coated with ICAM-1 and stimulated with mAb KIM-127 inhibited almost completely the morphological changes induced by LFA-1, and the majority of cells remained round shaped (Figure 3A). In contrast with its dra- 


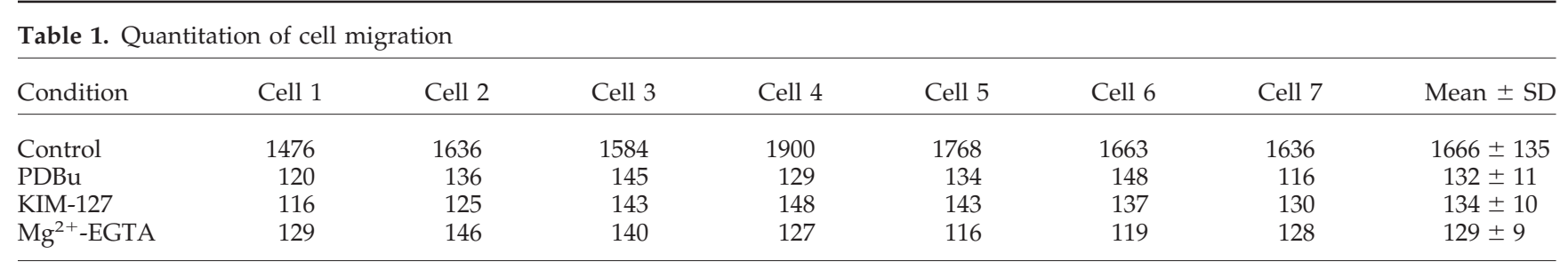

T lymphoblasts were plated on ICAM-1-Fc-coated plastic dishes and allowed to adhere for 45 min in the presence of the indicated stimuli before filming starts. Films of cells were generated from stacks of individual digital images (frames) taken every $20 \mathrm{~s}$ for $2 \mathrm{~h}$ in an Zeiss Axiovert 135 video microscope using the IP-Lab-Spectrum software. The distances migrated by individual cells were quantitated using the Cell Tracking software extension developed by Tim Hutton. Numbers represent average speeds of migration of individual cells over a 20-min period in micrometers per hour.

matic effects on lymphoblast morphology and polarization, genistein did not affect significantly the adhesion of these cells to ICAM-1 (Figure 3B). These results suggest that tyrosine kinase activity is required for LFA-1-induced changes in the morphology of lymphoblasts.

\section{LFA-1 Stimulates FAK and PYK-2 Tyrosine Kinase Activity in Human Lymphoblasts}

Because a tyrosine kinase seemed to be involved in the signaling from LFA-1, we examined the effect of stimulation of LFA-1 on the tyrosine kinase activities present in lymphoblasts. Cells plated on dishes coated with ICAM-1 were treated with the activating $\mathrm{mAb}$ KIM-127 for $30 \mathrm{~min}$ and lysed. $\operatorname{Tyr}(\mathrm{P})$ proteins were immunoprecipitated from the cell lysates with the $\mathrm{mAb}$ PY20, and the resulting immune complexes were incubated with $\left[\gamma^{-}{ }^{32} \mathrm{P}\right] \mathrm{ATP}$, analyzed by SDS-PAGE, and subjected to autoradiography. In the immunoprecipitates obtained from KIM-127-treated cells, we observed strong phosphorylation of several bands in the $M_{\mathrm{r}}$ 110,000-180,0000 and 70,000-80,000 ranges (Figure 4, left panel). Results identical to those shown in Figure 4, left panel, were obtained when immunoprecipitates were prepared using a different anti-Tyr $(\mathrm{P})$ mAb (PY72).

To determine whether the tyrosine kinases FAK and PYK-2 were among the $M_{\mathrm{r}} 110,000-180,000$ bands in the PY20 immune complexes, ${ }^{32} \mathrm{P}$-labeled Tyr(P)-proteins obtained from parallel cell cultures, unstimulated or treated for $30 \mathrm{~min}$ with $\mathrm{KIM}-127 \mathrm{mAb}$, were eluted from the complexes by denaturation in the presence of SDS and subsequently reimmunoprecipitated either with the C-20 anti-FAK (FAK) or with the C-19 anti-PYK-2 (PYK-2) polyclonal antibodies, or with nonimmune rabbit serum (NIS; Figure 4) (or nonimmune goat serum). C-20 and C-19 antibodies are specific for the C-terminal region of FAK and PYK-2, respectively (see MATERIALS AND METHODS). The results obtained demonstrate that both FAK and PYK-2 are constituents of the $M_{\mathrm{r}} 110,000-$
$180,000 \operatorname{Tyr}(\mathrm{P})$ bands induced after activation of LFA-1. At the percentage of SDS-PAGE used in this experiment $(8 \%)$, bands corresponding to FAK and PYK-2 showed very similar electrophoretic mobilities, but at lower SDS-PAGE percentages, PYK-2 migrated at a slightly lower $M_{\mathrm{r}}$ compared with FAK (Earp et al., 1995).

To confirm directly that LFA-1 stimulates FAK activity, lysates of KIM-127-treated lymphoblasts were incubated with the anti-FAK antibody C-20, and the C-20 immunoprecipitates were incubated with $\left[\gamma^{-32} \mathrm{P}\right] \mathrm{ATP}$ and analyzed by SDS-PAGE. As observed in Figure 5A (IP: C-20), FAK activity increases upon KIM-127 stimulation. No kinase activity was detected when the lysates were immunoprecipitated with nonimmune rabbit serum (Figure 5A, IP: NIS). To further confirm that the radiolabeled $125-\mathrm{kDa}$ band was FAK, we eluted this band by denaturation and reprecipitated the eluted proteins with the mAb a-FAK, an antibody that recognizes an epitope in the kinase domain of FAK (Figure 5A, IP: C-20 and r-IP: a-FAK). The reimmunoprecipitation of the $125-\mathrm{kDa}$ radiolabeled band in these experiments confirmed that it is phosphorylated FAK (Figure 5A, IP: C-20 and r-IP: a-FAK). No band was detected when the C-20 immunoprecipitate was reimmunoprecipitated with nonimmune rabbit serum (Figure 5A, IP: C-20 and r-IP: NIS). A similar increase in FAK activity after in vitro kinase assays was also observed when lysates of lymphoblasts stimulated with KIM-127 were immunoprecipitated with A-17, a polyclonal antibody that recognizes an epitope in the $\mathrm{N}$ terminus of FAK (Figure 5A, IP: A-17) or with mAb 2A7, an antibody reactive with the C-terminal sequence of FAK. SDS-PAGE and fluorography of FAK immunoprecipitates obtained from $\left[{ }^{35} \mathrm{~S}\right]$ methionine metabolically labeled cells prepared in parallel with those used for the kinase assays verified that similar amounts of FAK were recovered before and after KIM-127 treatment (Figure 5A, ML: ${ }^{35}$ S-Met and IP: C-20). 

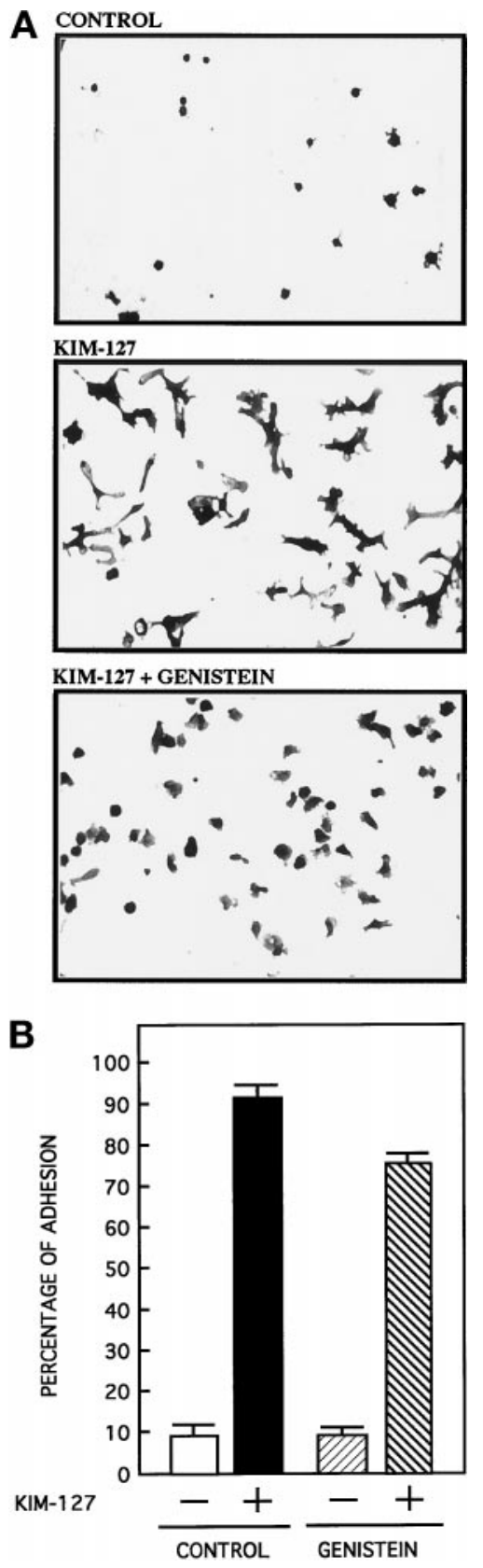

Figure 3. Tyrosine kinase inhibitor genistein blocks KIM-127stimulated polarization of lymphoblasts. (A) Lymphoblasts were washed in RPMI 1640 medium and then treated as follows: pretreated for $2 \mathrm{~h}$ with $0.3 \%$ DMSO and then plated on ICAM-1-Fccoated dishes for $60 \mathrm{~min}$ (CONTROL); pretreated for $2 \mathrm{~h}$ with $0.3 \%$ DMSO, plated on ICAM-Fc-coated dishes, and stimulated for 60 min with $10 \mu \mathrm{g} / \mathrm{ml} \mathrm{mAb}$ KIM-127 (KIM-127); and pretreated for $2 \mathrm{~h}$ with $30 \mu \mathrm{M}$ of genistein dissolved in DMSO, plated on ICAM-Fccoated dishes, and stimulated for $60 \mathrm{~min}$ with $10 \mu \mathrm{g} / \mathrm{ml} \mathrm{mAb}$ KIM-127 (KIM-127 + GENISTEIN). Cells were fixed and stained with $0.5 \%$ crystal violet in $20 \%$ methanol before photography. A representative experiment is shown. (B) Quantification of the cell adhesion assays represented in A was carried out as specified in MATERIALS AND METHODS. The results are the mean \pm SEM of three independent experiments.

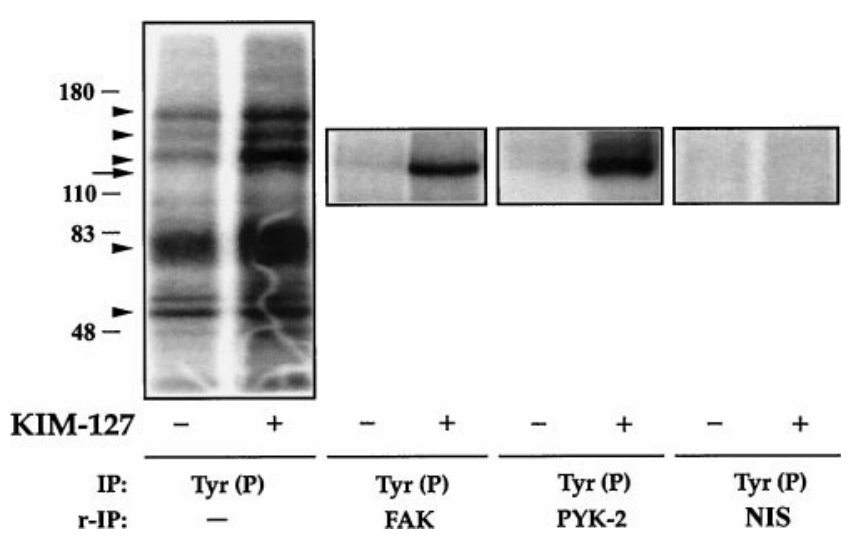

Figure 4. Presence of FAK and PYK-2 in anti-Tyr $(\mathrm{P})$ immunoprecipitates from $T$ cells after activation of LFA-1. T lymphoblasts $(50 \times$ $10^{6}$ cells) plated on ICAM-1-Fc-coated plastic dishes were allowed to adhere for $30 \mathrm{~min}$ in the absence $(-)$ or presence $(+)$ of $10 \mu \mathrm{g} / \mathrm{ml}$ $\mathrm{mAb}$ KIM-127. The cells were then lysed, the extracts were immunoprecipitated (IP) with the PY20 anti-Tyr(P) mAb [IP: Tyr(P)], and kinase reactions were performed as described in MATERIALS AND METHODS. In parallel cultures of lymphoblasts, which were allowed to adhere to ICAM-1-FC and stimulated or not with KIM-127 as above, after the kinase reactions were carried out, the major $\operatorname{Tyr}(\mathrm{P})$-labeled bands were eluted from the PY20 immunocomplexes by boiling the pellet in $100 \mu \mathrm{l}$ of a solution containing $10 \mathrm{mM}$ Tris, $\mathrm{pH} 7.4$ and $1 \%$ SDS. Denatured $\operatorname{Tyr}(\mathrm{P})$ proteins were then reimmunoprecipitated (r-IP) with the anti-FAK C-20 to confirm the presence of FAK [IP: $\operatorname{Tyr}(\mathrm{P})$ and r-IP: FAK], with the anti-PYK-2 C-19 to confirm the presence of PYK-2 [IP: $\operatorname{Tyr}(\mathrm{P})$ and r-IP: PYK-2], or with nonimmune rabbit serum control [IP: Tyr (P) and r-IP: NIS]. After SDS-PAGE of PY20 immunoprecipitates and C-20 and C-19 reimmunoprecipitates, gels were subjected to autoradiography to detect total phosphotyrosines FAK and PYK-2, respectively. The position of the major phosphorylated bands in the gel is indicated with arrowheads. The FAK and PYK-2 position is indicated by an arrow. Molecular mass markers (in kilodaltons) are shown on the left. The results are representative of three independent experiments.

Quantitative densitometric scanning showed that activation of LFA-1 induced by treatment of the T lymphoblasts with mAb KIM-127 induced a 2.5- \pm 0.4 -fold $(\mathrm{n}=3)$ and 2.4- \pm 0.4 -fold $(\mathrm{n}=4)$ increase in the phosphorylation of FAK in immunoprecipitates obtained with the C-20 and A-17 polyclonal antibodies, respectively (Figure 5B). An increase in the activity of FAK after KIM-127 treatment of lymphoblasts cells was also demonstrated when lysates from control and KIM-127-stimulated cells were immunoprecipitated with the C-20 antibody, and kinase activity was determined by the ability of the immunoprecipitates to phosphorylate exogenously added substrate poly-Glu-Tyr (4:1) (Figure 5C).

To further investigate the stimulation of PYK-2 activity through LFA-1, lysates of KIM-127-treated lymphoblasts were incubated with the C-19 antiPYK-2 polyclonal antibody. PYK-2 immunoprecipitates were incubated with $\left[\gamma^{32} \mathrm{P}\right] \mathrm{ATP}$ and analyzed by SDS-PAGE. As observed in Figure 6A, in contrast 
Figure 5. KIM-127 induces stimulation of FAK tyrosine kinase activity. (A) T lymphoblasts plated on ICAM-1-Fc-coated plastic dishes were allowed to adhere for $60 \mathrm{~min}$ in the absence (-) or presence $(+)$ of $10 \mu \mathrm{g} / \mathrm{ml} \mathrm{mAb}$ KIM127. The cells were then lysed, the extracts were incubated with the C-20 antibody (IP: C-20) or with nonimmune rabbit serum control (IP: NIS), and kinase reactions were carried out as described in MATERIALS AND METHODS. In parallel cultures, after the kinase reaction was performed, the major 125-kDa labeled band was eluted from the C-20 immunocomplex by boiling the pellet in $100 \mu \mathrm{l}$ of a solution containing 10 mM Tris, pH 7.4 and 1\% SDS. Denatured FAK was then reimmunoprecipitated with the mAb a-FAK to confirm that the labeled band was phosphorylated FAK (IP: C-20 and r-IP: a-FAK) or with nonimmune serum control (IP: C-20 and r-IP: NIS). Lysates obtained from cells untreated or treated with KIM-127 were also immunoprecipitated with the A-17 polyclonal antibody (IP: A-17) and then subjected to in vitro kinase reactions performed as described in MATERIALS AND METHODS. FAK levels were determined by metabolic labeling of parallel cultures of cells with [ $\left.{ }^{35} \mathrm{~S}\right] \mathrm{methionine}$ (ML: $\left.{ }^{35} \mathrm{~S}-\mathrm{Met}\right)$ and immunoprecipitation of the labeled extracts with the C-20 anti-FAK antibody (IP: C-20). The position of FAK is indicated by an arrow. (B) Quantification by densitometric scanning of the effect of KIM-127 on FAK activity. FAK was immunoprecipitated with either C-20 (left panel) or A-17 (right panel) antibodies as in A, and the in vitro kinase reactions were carried out as described in MATERIALS AND METHODS. Values are the mean \pm SEM of three independent experiments and are expressed as fold stimulation above control. (C) In vitro kinase reactions of the C-20 FAK immunoprecipitates were performed in the presence of the tyrosine kinase substrate poly-Glu-Tyr (4:1). Phosphorylation of poly-Glu-Tyr (4:1) was carried out after a 15 -min incubation with $\left[\gamma^{-32}\right.$ P]ATP as described in MATERIALS AND METHODS. A representative experiment is shown.

to FAK, PYK-2 shows relatively high basal activity in unstimulated cells that is further increased upon LFA-1 activation. No kinase activity was detected when the lysates were immunoprecipitated with nonimmune goat serum (Figure 6A, NIS). Immunoblotting with N-19 antibody or C-19 antibody of PYK-2 immunoprecipitates prepared in parallel with those used for the kinase assays verified that similar amounts of PYK-2 were recovered after KIM-127 treatment (Figure 6A, IP: C-19 and WB: C-19). Densitometric scanning showed that KIM-127 induced a 7.5- \pm 1.4 -fold $(n=5)$ increase in the phosphorylation of PYK-2 (Figure 6B). Accordingly, we also observed a strong increase in the ability of PYK-2 immunoprecipitates to phosphorylate the exogenous substrate poly-Glu-Tyr (4:1) when cells were stimulated with KIM-127 (Figure 6C). No increase in FAK or PYK-2 phosphorylation was observed when lymphoblasts plated on BSA or polyL-lysine were stimulated with $10 \mu \mathrm{g} / \mathrm{ml} \mathrm{mAb}$ KIM127 or when the cells plated on ICAM-1 were stimulated with $10 \mu \mathrm{g} / \mathrm{ml}$ control antibody. Taken together, these results show that both FAK and PYK-2 increased their tyrosine kinase activities upon LFA-1 activation.

\section{Time Course of LFA-1-stimulated FAK and PYK-2 Tyrosine Kinase Activities}

To study in detail the kinetics of activation of FAK and PYK-2, lymphoblasts plated on dishes coated with ICAM-1 were treated with the activating $\mathrm{mAb}$ KIM-127 for different times and lysed. The lysates were incubated with $\mathrm{C}-20$ and C-19 antibodies to immunoprecipitate FAK and PYK-2, respectively. The resulting immune complexes were incubated with $\left[\gamma_{-}{ }^{32} \mathrm{P}\right]$ ATP, analyzed by SDS-PAGE, and subjected to autoradiography. As observed in Figure 7, A and B (upper panels), KIM-127 stimulates the activity of FAK with a kinetics different from that observed for PYK-2. The increase in the activity of FAK reached a maximum within $45 \mathrm{~min}$ and remained sustainedly at this maximal level for at least $60 \mathrm{~min}$ (Figure 7A, upper panel). In contrast, the increase in PYK-2 activity reached a maximum 30 min after stimulation with KIM-127, decreasing at longer times (Figure 7B, upper panel). SDS-PAGE and fluorography of anti-FAK immunoprecipitates of $\left.{ }^{35} \mathrm{~S}\right]$ methionine-labeled cells (Figure 7A, lower panel) and immunoblotting with C-19 antibody of anti-PYK-2 immunoprecipitates (Figure 7B, lower panel), prepared in parallel with those used for the 
A

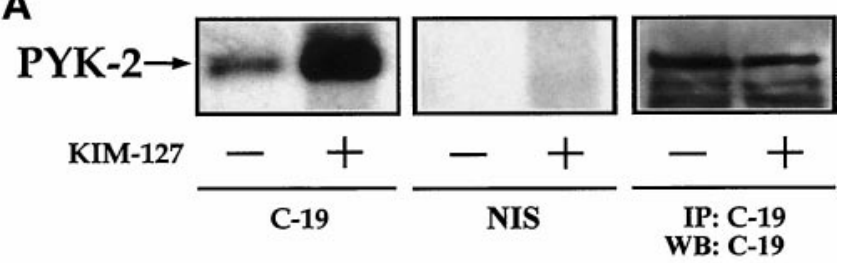

B

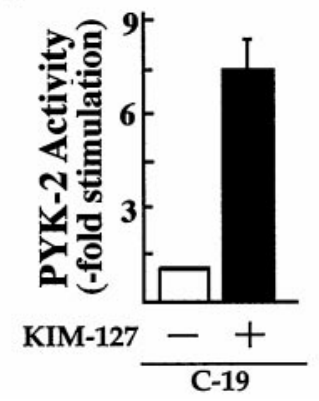

C

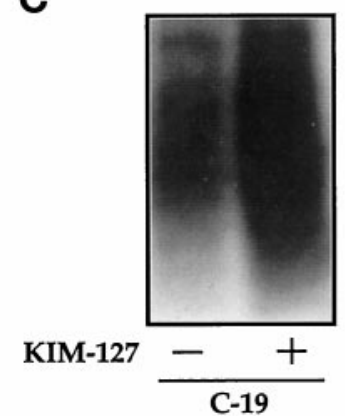

Figure 6. KIM-127 induces stimulation of PYK-2 tyrosine kinase activity. (A) T lymphoblasts plated on ICAM-1-Fc-coated plastic dishes were allowed to adhere for $30 \mathrm{~min}$ in the absence $(-)$ or presence $(+)$ of $10 \mu \mathrm{g} / \mathrm{ml}$ mAb KIM- 127 . The cells were then lysed, the extracts were incubated with C-19 antibody to immunoprecipitate PYK-2 (C-19) or with nonimmune goat serum as a control (NIS), and kinase reactions were performed as described in MATERIALS AND METHODS. PYK-2 levels were determined by immunoprecipitation (IP) with the C-19 anti-PYK-2 antibody and Western blot analysis (WB) with C-19 anti PYK-2 antibody. The position of PYK-2 is indicated with an arrow. The results shown are representative of seven independent experiments. (B) Quantification by densitometric scanning of the effect of KIM-127 on PYK-2 activity. PYK-2 was immunoprecipitated with the C-19 antibody and an in vitro kinase reaction carried out as described in MATERIALS AND METHODS. Values are the mean \pm SEM of five independent experiments and are expressed as fold stimulation above control. (C) In vitro kinase reactions of the C-19 PYK-2 immunoprecipitates were performed in the presence of the tyrosine kinase substrate poly-Glu-Tyr $(4: 1)$. Phosphorylation of poly-Glu-Tyr (4:1) was carried out after a 15-min incubation with $\left[\gamma^{32} \mathrm{P}\right]$ ATP as described in MATERIALS AND METHODS. A representative experiment is shown.

kinase assays, confirmed that similar amounts of FAK and PYK-2 kinases were recovered after different times of KIM-127 treatment.

\section{FAK and PYK-2 Are Redistributed after Activation of LFA-1 and Colocalize with the MTOC}

To study further the possible role of FAK and PYK-2 in the morphological changes observed in lymphoblasts, we examined the localization of these tyrosine kinases in resting and stimulated cells. Lymphoblasts plated on ICAM-1, unstimulated or treated with $\mathrm{Mg}^{2+}$-EGTA, were stained by double-labeling immunofluorescence with either C-20 rabbit polyclonal antiFAK antibody or C-19 goat polyclonal anti-PYK-2 antibody and with an anti- $\alpha$-tubulin $\mathrm{mAb}$, as described
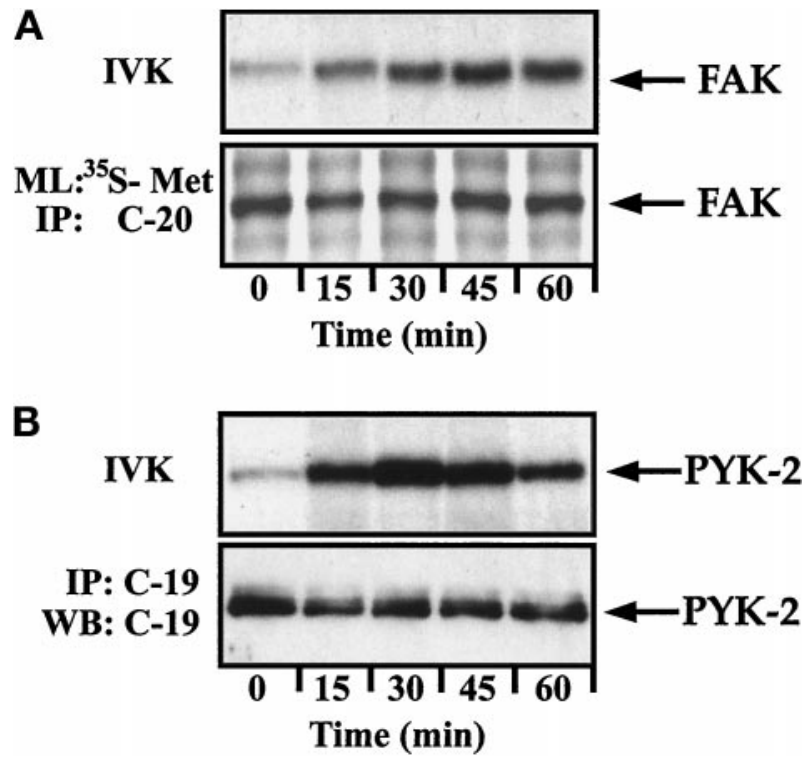

Figure 7. Time course of LFA-1-stimulated FAK and PYK-2 activities in lymphoblasts. T cells plated on ICAM-1-Fc-coated plastic dishes were stimulated for the indicated times with $10 \mu \mathrm{g} / \mathrm{ml} \mathrm{mAb}$ KIM-127 and lysed. (A) Lysates were incubated with the C-20 antibody to immunoprecipitate FAK, and kinase activities in the resulting immunoprecipitates were measured by in vitro kinase reaction performed as described in MATERIALS AND METHODS (IVK). FAK levels were determined in parallel cultures by metabolically labeling the cells with $\left.{ }^{35} \mathrm{~S}\right]$ methionine and immunoprecipitation of the labeled extracts with the C-20 antibody (ML: ${ }^{35}$ S-Met and IP: C-20). The position of FAK is indicated with an arrow. (B) Lysates were incubated with the C-19 antibody to immunoprecipitate PYK-2, and kinase activities in the resulting immunoprecipitates were measured by in vitro kinase reactions (IVK). PYK-2 immunoprecipitates were also analyzed by SDS-PAGE, followed by transfer to Immobilon membranes and Western blotting with antiPYK-2 antibodies (IP: C-19 and WB: C-19). A representative experiment is shown. The position of PYK-2 is indicated with an arrow.

in MATERIALS AND METHODS. In unstimulated cells, FAK (Figure 8A; unstimulated, FAK) and PYK-2 (Figure 8B; unstimulated, PYK-2) exhibited a diffuse distribution. Interestingly, in these cells, PYK-2 also localized to the cell-cell contact area (Figure 8B, unstimulated, PYK-2), as reported by others (Sasaki et al., 1995). In cells in which LFA-1 was activated, FAK (Figure 8A; stimulated, FAK) and PYK-2 (Figure 8B; stimulated, PYK-2) are redistributed mainly to the region between the cell body and the stemming projection. Similar staining was observed with the polyclonal antibodies A-17 and N-19, which recognize sequences in the N-termini of FAK and PYK-2, respectively. This characteristic staining was specific, because it was not observed in cells labeled with control nonimmune rabbit [Figure 8A, stimulated, NIS (rabbit)] or goat [Figure 8B; stimulated, NIS (goat)] sera. Interestingly, costaining with an anti- $\alpha$-tubulin antibody showed that the location of FAK and PYK-2 in stimulated cells coincides with the position of the 
A
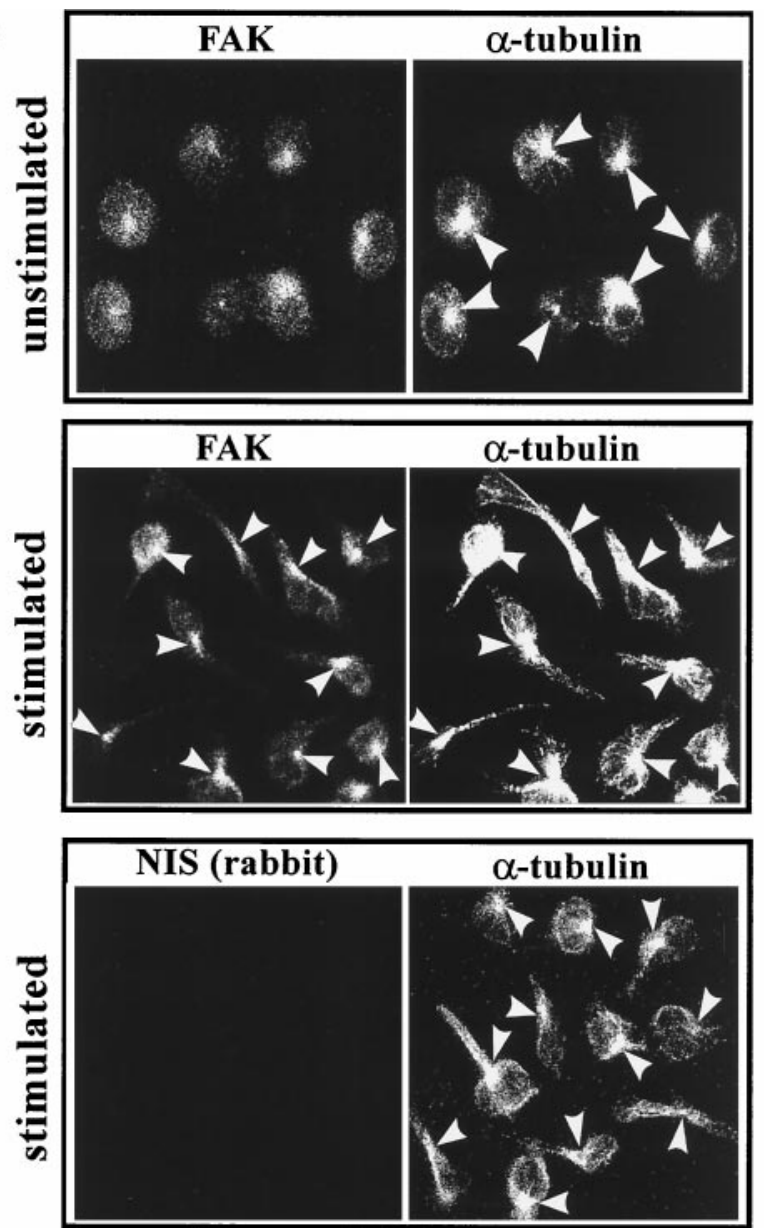

B
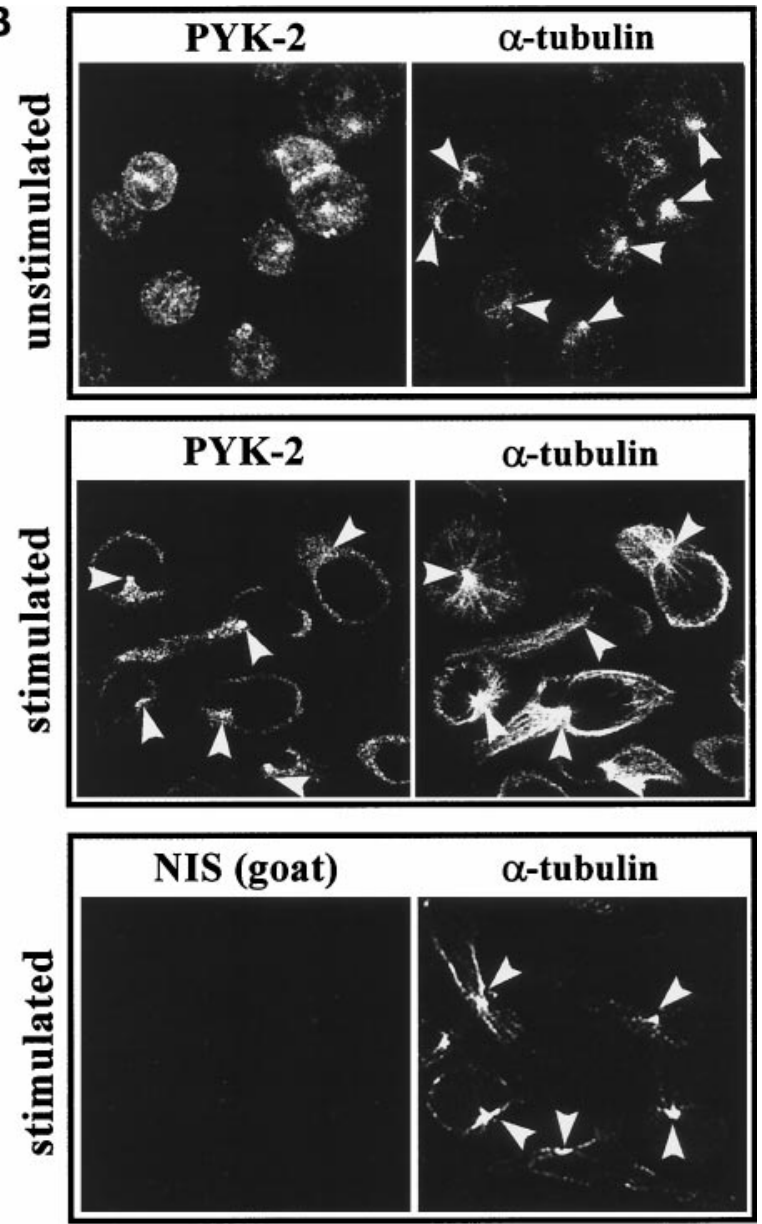

Figure 8. FAK and PYK-2 colocalize with the MTOC in polarized lymphoblasts. Lymphoblasts were allowed to adhere onto ICAM-1-Fccoated dishes for 60 min either in HEPES-NaCl buffer containing $1 \mathrm{mM} \mathrm{Mg}^{2+}$ and $1 \mathrm{mM} \mathrm{Ca}^{2+}$ (unstimulated) or in $\mathrm{HEPES}-\mathrm{NaCl}$ containing $10 \mathrm{mM} \mathrm{Mg}^{2+}$ and $1 \mathrm{mM}$ EGTA (stimulated). (A) The cells were fixed, permeabilized, and double stained with C-20 rabbit polyclonal antibody against FAK (FAK) or with a control rabbit nonimmune serum (NIS rabbit) and with an anti- $\alpha$-tubulin mAb ( $\alpha$-tubulin) as specified in MATERIALS AND METHODS. (B) The cells were fixed, permeabilized, and doubled stained with C-19 goat polyclonal antibody against PYK-2 (C-19) or with a control goat nonimmune serum (NIS goat) and with an anti- $\alpha$-tubulin mAb ( $\alpha$-tubulin) as specified in MATERIALS AND METHODS. Arrowheads indicate the positions of the MTOC in representative cells.

MTOC in polarized lymphoblasts (Figure $8, \mathrm{~A}$ and B, stimulated, $\alpha$-tubulin). Similar results were obtained when single immunofluorescences for FAK, PYK-2, or $\alpha$-tubulin were performed, ruling out cross-detection of fluorescence.

\section{Actin and Microtubular Cytoskeletal Networks Are Involved in the Morphological Changes Induced by Stimulation of LFA-1}

To evaluate the importance of cytoskeletal integrity in the observed changes in cell morphology that take place in lymphoblasts upon stimulation of activation of LFA-1, we studied the effect of different cytoskeletal perturbing agents in this process. Lymphoblasts were pretreated with cytochalasin $\mathrm{D}(2.5 \mu \mathrm{M})$, a drug which disrupts the actin cytoskeleton, colchicine $(10 \mu \mathrm{M})$, or taxol (1 $\mu \mathrm{M})$, drugs that disrupt and stabilize the tubulin cytoskeleton, respectively, and the cultures were subsequently stimulated with the mAb KIM-127. At the concentrations used, all the agents exerted only a slight inhibitory effect on the adhesion of lymphoblasts to ICAM-1. However, as shown in Figure 9A, treatment with all these agents blocked the morphological changes in response to the stimulation with KIM-127.

The changes in morphology observed in lymphoblasts upon stimulation of activation of LFA-1 take place concomitantly with a redistribution of FAK and PYK-2 to the MTOC (Figure 8, A and B). We performed immunofluorescence experiments to study whether treatment with cytochalasin D or colchicine had any effect on the distribution of FAK and PYK-2. 
A

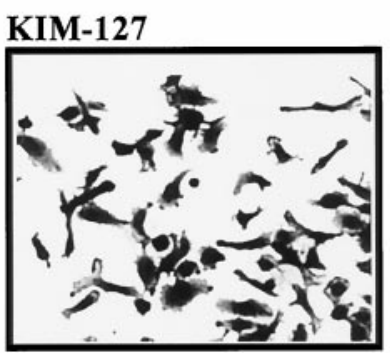

KIM-127 + CYT D
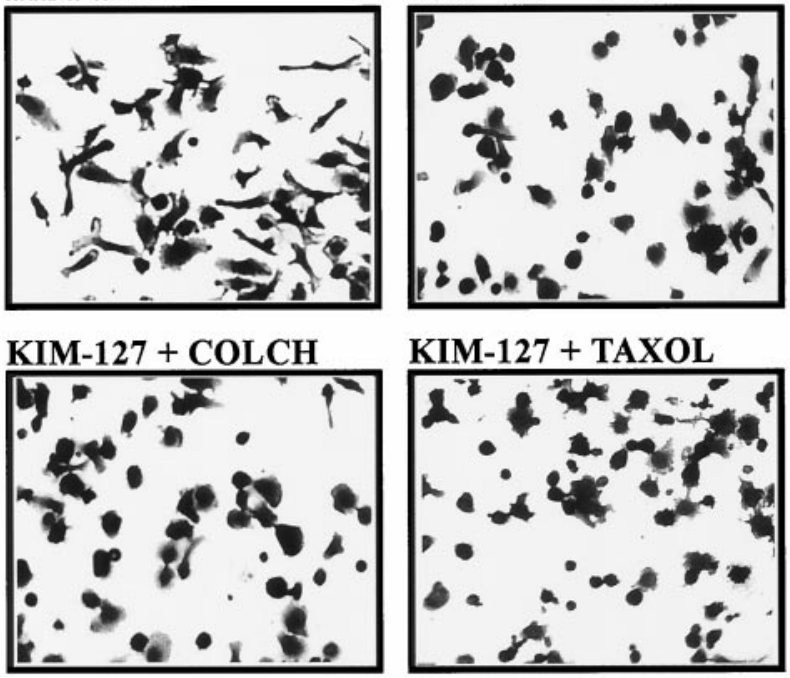

KIM-127 + TAXOL

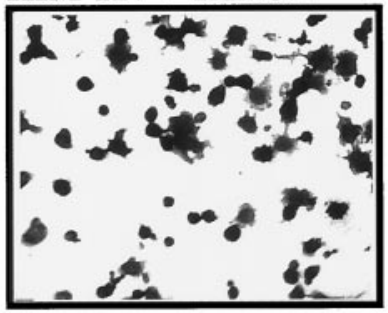

B
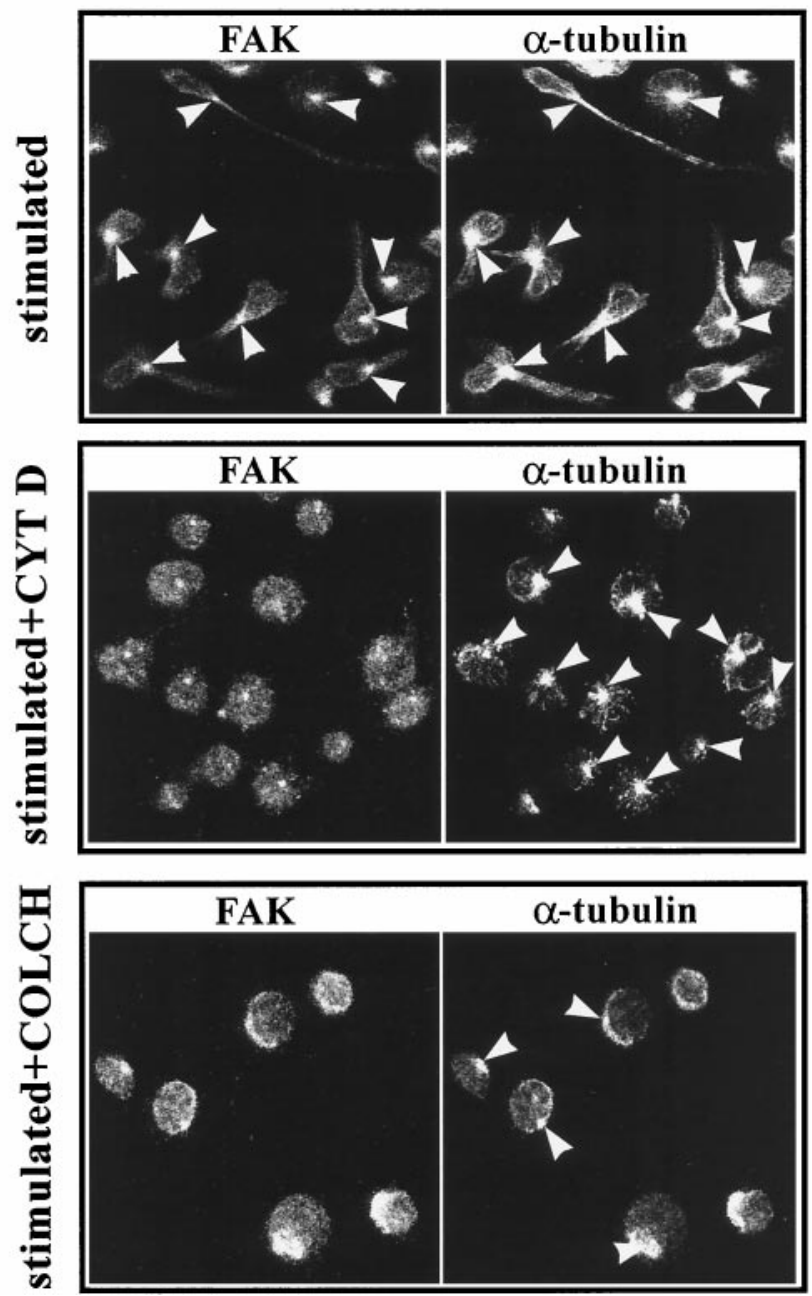

Figure 9. Cytoskeletal interfering agents block LFA-1-dependent polarization of lymphoblasts and reduce translocation of FAK and PYK-2 to the MTOC. (A) T Lymphoblasts were washed in RPMI 1640 medium and then pretreated for $4 \mathrm{~h}$ with $0.3 \%$ DMSO (KIM127), with $2.5 \mu \mathrm{M}$ cytochalasin D dissolved in DMSO (KIM-127 + CYT D), with $10 \mu \mathrm{M}$ colchicine dissolved in DMSO (KIM-127 + $\mathrm{COLCH}$ ), or with $1 \mu \mathrm{M}$ taxol dissolved in DMSO (KIM-127 + TAXOL). Cells were subsequently plated on ICAM-Fc-coated dishes and stimulated for $60 \mathrm{~min}$ with $10 \mu \mathrm{g} / \mathrm{ml} \mathrm{mAb} \mathrm{KIM}-127$ Attached cells were fixed and stained with $0.5 \%$ crystal violet in $20 \%$ methanol before photography. A representative experiment is shown. (B and C) T Lymphoblasts were washed in RPMI medium and then pretreated for $4 \mathrm{~h}$ with $0.3 \%$ DMSO (stimulated), with 2.5 $\mu \mathrm{M}$ cytochalasin D (stimulated $+\mathrm{CYT} \mathrm{D}$ ), or with $10 \mu \mathrm{M}$ colchicine (stimulated + COLCH). After this pretreatment, cells were washed in HEPES- $\mathrm{NaCl}$ buffer, plated on ICAM-1-Fc-coated dishes, and stimulated for $60 \mathrm{~min}$ with $10 \mathrm{mM} \mathrm{Mg}{ }^{2+}$ plus $1 \mathrm{mM}$ EGTA. The cells were fixed, permeabilized, and doubled stained with C-20 rabbit polyclonal antibody against FAK (B, FAK) or with C-19 goat polyclonal antibody against PYK-2 (C, PYK-2) and with an anti- $\alpha$-tubulin $\mathrm{mAb}$ (B and $\mathrm{C}, \alpha$-tubulin). Immunofluorescence samples were analyzed by confocal laser microscopy as specified in MATERIALS AND METHODS. Arrowheads indicate the position of the MTOC. A representative experiment is shown.
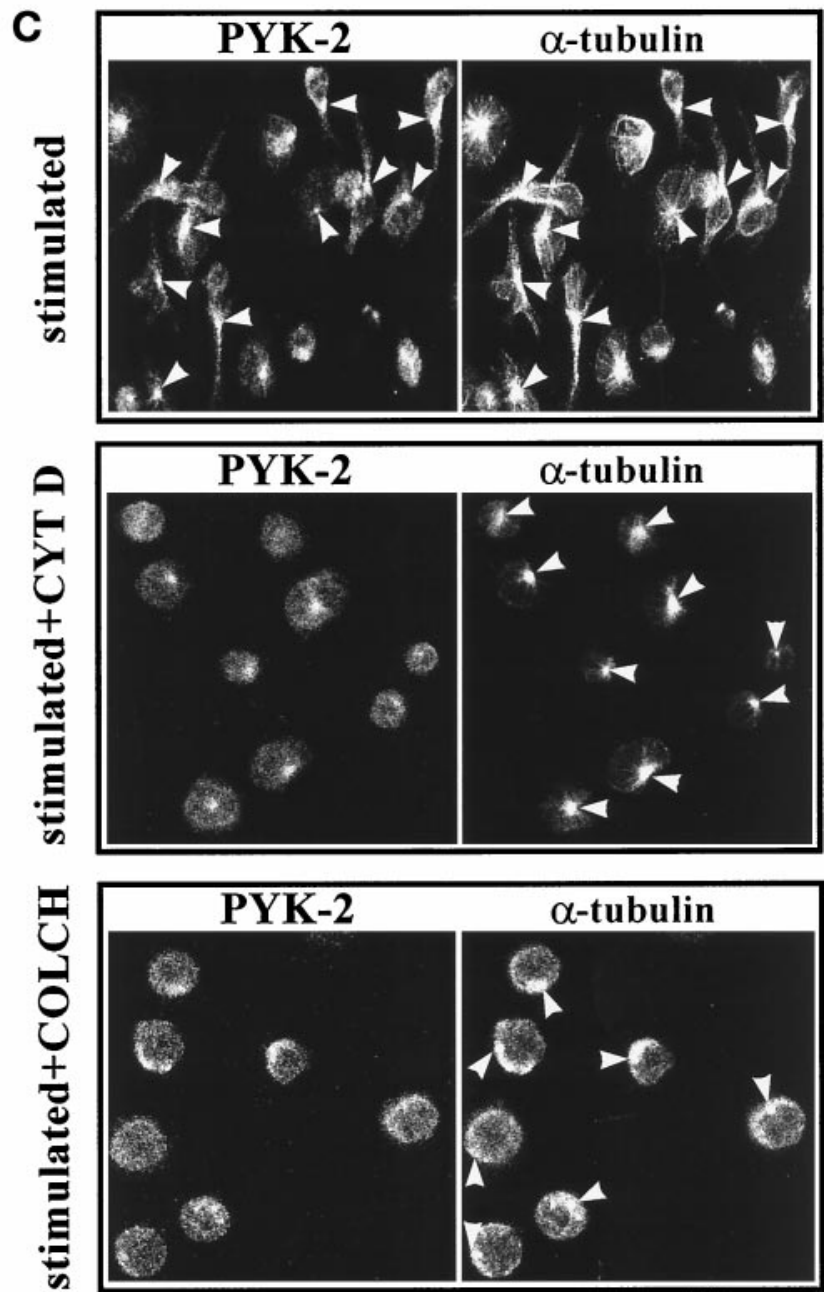
For this purpose, lymphoblasts were pretreated either with vehicle DMSO (Figure 9, B and C, stimulated), cytochalasin D (Figure 9, B and C, stimulated + CYT D), or colchicine (Figure 9, B and C, stimulated + $\mathrm{COLCH}$ ), and the cultures were subsequently stimulated with $\mathrm{Mg}^{2+}$-EGTA to stimulate LFA-1. In contrast with cells pretreated with DMSO, which display a highly polarized morphology, with long cellular projections and the characteristic staining of FAK and PYK-2 colocalizing with the MTOC (Figure 9, B and C, stimulated), cytochalasin D-treated (Figure 9, B and C, stimulated + CYT D) and colchicine-treated cells (Figure $9, \mathrm{~B}$ and $\mathrm{C}$, stimulated $+\mathrm{COLCH}$ ) showed a rounded morphology. Interestingly, in the cytochalasin D- and colchicine-treated cells some FAK and PYK-2 staining remained colocalizing with the MTOC, but the intensity of this staining was lower in comparison with control cells (Figure 9, B and C).

\section{LFA-1-mediated Activation of FAK and PYK-2 Requires Cytoskeletal Integrity}

Because cytoskeletal disrupting agents affect the relocation of FAK and PYK-2 to the MTOC in lymphoblasts, we also studied the effect of these agents on the activation of FAK and PYK-2. For this purpose, lymphoblasts were pretreated with cytochalasin D (2.5 $\mu \mathrm{M})$, colchicine $(10 \mu \mathrm{M})$, or taxol $(1 \mu \mathrm{M})$. The cells were subsequently plated on dishes coated with ICAM-1 and treated with the activating mAb KIM127. As shown in Figure 10, A and B (upper panels), all the agents blocked the increase in FAK and PYK-2 activity in response to the stimulation of LFA-1. Taken together, these results suggest that the reorganization of the actin and tubulin networks that takes place after stimulation of LFA-1 is required for FAK and PYK-2 activation.

\section{DISCUSSION}

Polarization of $\mathrm{T}$ lymphocytes upon interaction with APCs or during chemokine directed transendothelial migration is a relevant phenomenon that is thought to contribute importantly to the specificity and effectiveness of immune responses (Geiger et al., 1982; del Pozo et al., 1996; Sánchez-Madrid and del Pozo, 1999). Cell polarization involves the conversion from a spherical to an elongated morphology, a process in which important changes in the organization of the cytoskeleton take place. In the present study we report that upon induction of activation of the $\beta 2$-integrin LFA- 1 , T lymphocytes undergo a dramatic polarization, characterized by the conversion from a spherical morphology, characteristic of the nonadherent cells, to an elongated morphology, characterized by the presence of a cell body and a long cellular extension. These morphological changes take place as a result of the interaction
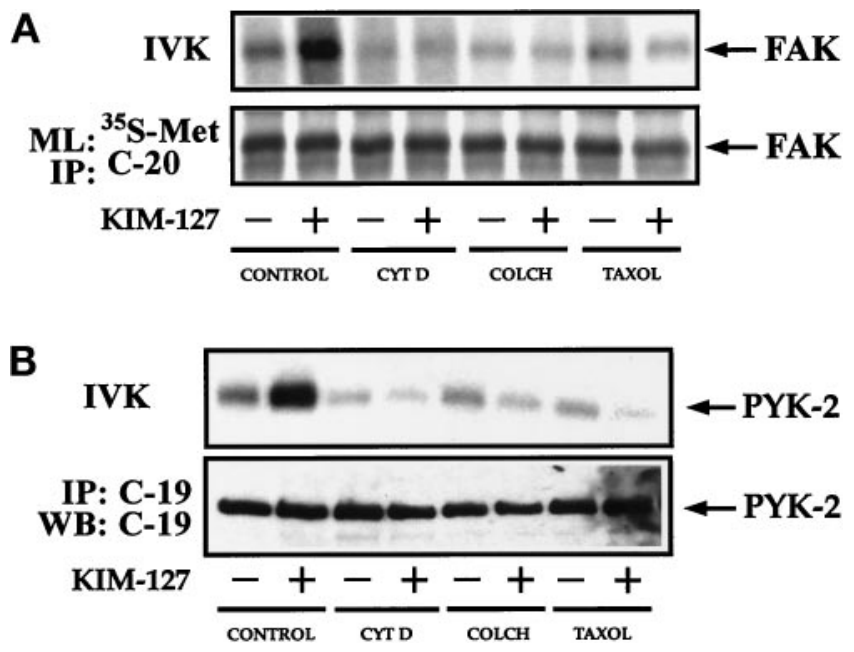

Figure 10. Cytoskeletal interfering agents block LFA-1-dependent increase in FAK and PYK-2 kinase activities. (A) T Lymphoblasts were washed in RPMI 1640 medium and then pretreated for $4 \mathrm{~h}$ with $0.3 \%$ DMSO (CONTROL), with $2.5 \mu \mathrm{M}$ cytochalasin D dissolved in DMSO (CYT D), with $10 \mu \mathrm{M}$ colchicine dissolved in DMSO (COLCH), or with $1 \mu \mathrm{M}$ taxol dissolved in DMSO (TAXOL). $\mathrm{T}$ cells were subsequently plated onto ICAM-1-Fc-coated dishes and allowed to adhere for $60 \mathrm{~min}$ in the absence $(-)$ or presence $(+)$ of $10 \mu \mathrm{g} / \mathrm{ml} \mathrm{mAb}$ KIM-127. Cells were lysed, and lysates were incubated with the C-20 antibody to immunoprecipitate FAK. Kinase activities in the resulting immunoprecipitates were measured by in vitro kinase reactions performed as described in MATERIALS AND METHODS (IVK, top). FAK levels were determined in parallel cultures by metabolic labeling the cells with $\left.{ }^{35} \mathrm{~S}\right]$ methionine and immunoprecipitation of the labeled extracts with C-20 antibody (ML: ${ }^{35}$ S-Met and IP: C-20, bottom). The position of FAK is indicated with an arrow. (B) T Lymphoblasts were pretreated as in A in the presence of DMSO (CONTROL), cytochalasin D (CYT D), colchicine (COLCH), or (TAXOL). T cells were subsequently plated onto ICAM-1-Fc-coated dishes and allowed to adhere for $30 \mathrm{~min}$ in the absence (-) or presence (+) of $10 \mu \mathrm{g} / \mathrm{ml} \mathrm{mAb}$ KIM-127. Cells were then lysed, and half of the lysates were incubated with C-19 antibody to immunoprecipitate PYK-2 and kinase reactions performed as described in MATERIALS AND METHODS (IVK, top). The other half of the lysates were also immunoprecipitated with C-19 antibody and analyzed by SDS-PAGE, followed by transfer of proteins to Immobilon membranes and Western blotting with anti-PYK-2 antibodies (IP: C-19 and WB: C-19, bottom). The position of PYK-2 is indicated with an arrow.

between activated LFA-1 integrin molecules with ligand ICAM-1, because they are not observed when cells are plated on poly-L-lysine. The induction of activation of the LFA-1 integrin on T lymphoblasts adhering to ICAM-1 also involves the conversion of the cells from a highly motile to a nonmotile phenotype. Furthermore, we demonstrate that binding of $\mathrm{T}$ lymphoblasts to the LFA-1 ligand ICAM-1 induces the activation and intracellular redistribution of the tyrosine kinases FAK and PYK-2.

The described changes in the adhesive capacity, morphology, and locomotive behavior in T lymphoblasts upon induction of activation of LFA-1 molecules take place using three different protocols for 
induction of activation of LFA-1 molecules, i.e., 1) the presence in the medium of divalent cation $\mathrm{Mg}^{2+}, 2$ ) incubation of cells with the $\beta 2$-specific stimulatory $\mathrm{mAb}$ KIM-127, and 3) the addition of the phorbol ester $\mathrm{PDBu}$. Interestingly, the first two protocols of induction of LFA-1 activation have been reported to affect mainly the affinity of this integrin, whereas the treatment with phorbol esters induces integrin adhesive capacity primarily through changes in avidity (Stewart et al., 1996). In parallel with the polarized morphology, we observed that the lymphocytes acquire a nonmotile phenotype. The cell polarization and the arrest of the migrating $\mathrm{T}$ lymphocytes seem to be related phenomena, which contribute to the proper function of $\mathrm{T}$ lymphocytes. Thus, after $\mathrm{T}$ cell antigen receptor engagement during interaction with APCs, a stop signal is delivered through LFA-1 that converts the migrating $\mathrm{T}$ lymphocytes into nonmotile cells. This process appears to be an important requisite for an adequate immune response (Dustin et al., 1997; LowinKropf et al., 1998).

To study whether a tyrosine kinase activity was required for the observed LFA-1-mediated increase in $\mathrm{T}$ cell adhesion and polarization, we used the specific tyrosine kinase inhibitor genistein. Pretreatment with genistein blocked the polarization of the lymphoblasts with $\mathrm{mAb}$ KIM-127, suggesting that the morphological changes induced through the integrin LFA-1 require a tyrosine kinase activity. Genistein, however, had no significant effect on the adhesion of these cells to ICAM-1. Because in these experiments we used the $\mathrm{mAb}$ KIM-127 to activate the integrin LFA-1, these results suggest either that adhesion mediated by LFA-1 in lymphoblasts does not require a genisteinsensitive tyrosine kinase activity and/or that the affinity of LFA-1 for ligand ICAM- 1 that is induced by KIM-127 treatment is high enough to maintain the cells strongly adhered, even when tyrosine kinases are inhibited.

We demonstrate for the first time that upon activation of LFA-1 and binding of T lymphocytes to ligand ICAM-1, the two related nonreceptor tyrosine kinases FAK and PYK-2 become activated. FAK and PYK-2 immunoprecipitates possess intrinsic autokinase activities and are able to phosphorylate exogenous substrates, such as the tyrosine kinase substrate poly-GluTyr (4:1). Because several studies have demonstrated that the major phosphorylation sites on FAK and PYK-2 (i.e., Tyr-397 and Tyr-402, respectively) are high-affinity binding sites for the $\mathrm{SH} 2$ domain of members of the Src kinase family (Richardson and Parsons, 1995), and Src members are able to phosphorylate FAK, it has been suggested that FAK and PYK-2 kinase activities could also reflect the presence of Src in the immunoprecipitates, rather than an intrinsic increase in their activities. Nevertheless, several lines of evidence indicate that this is not the case in our assays.
First, in the lysis buffer in which our experiments were carried out, which contains the nonionic detergent Triton X-100 (see MATERIALS AND METHODS), the interaction between Src and FAK is minimal (Rodríguez-Fernández and Rozengurt, 1998; Schlaepfer et al., 1998). Second, when we used in our in vitro phosphorylation assays pyrazolopyrimidine, a novel specific inhibitor of Src kinases, we did not observe any inhibition in FAK activity at concentrations that virtually abolished Src kinase activity in parallel Src immunoprecipitates (Rodríguez-Fernández and Rozengurt, 1998). Therefore, the previous results strongly suggest that the increases in FAK and PYK-2 tyrosine kinases induced upon activation of integrin LFA-1 cannot be attributed to the presence of Src in the immunoprecipitates.

Several groups have shown that in leukocytes and other cells FAK and PYK-2 become tyrosine phosphorylated and activated upon stimulation of members of the $\beta 1, \beta 3$, and $\beta 5$ family of integrins (Kornberg et al., 1991; Guan and Shalloway, 1992; Hanks et al., 1992; Lipfert et al., 1992; Schaller et al., 1992; Shattil et al., 1994; Maguire et al., 1995; Li et al., 1996; Astier et al., 1997; Gismondi et al., 1997; Ma et al., 1997). Furthermore, it has been shown that fakB, a putative homologue of FAK present in lymphocytes, is regulated by the $\beta 2$-integrin LFA-1 (Kanner et al., 1994; Kanner, 1996). However, to our knowledge there are no reports demonstrating activation of FAK and/or PYK-2 upon engagement of a member of the $\beta 2$ family of integrins. Although the precise mechanism by which integrins are able to activate FAK or PYK-2 is not known, the $\mathrm{N}$-terminal region of FAK has been shown to associate in vitro with peptides corresponding to cytoplamic segments of $\beta 1-, \beta 2-$, and $\beta 3$-integrin subunits (Schaller et al., 1995). It has been speculated that the direct interaction with the cytoplasmic domain of the integrins could contribute to the activation of FAK (Schaller et al., 1995).

In polarized $\mathrm{T}$ lymphoblasts the activation of FAK and PYK-2 occurs in parallel with a redistribution of these kinases from a relatively diffuse localization in the cytoplasm to a location close to or in association with the MTOC of the lymphocytes. The MTOC is a critical organizing point within the cell, which becomes reoriented during cell polarization, and is thought to participate in the redistribution and concentration of surface molecules in membrane caps, including different adhesion receptors (Dustin et al., 1997; Sánchez-Madrid and del Pozo, 1999). Furthermore, several studies have suggested that the MTOC helps position the $\mathrm{T}$ cell secretory apparatus. For example, it was observed that reorientation of the MTOC was followed by the polarized concentration of cytokines and cytotoxic mediators at the T cell-APC surface (Kupfer et al., 1991). 
It has been reported that engagement of $\mathrm{T}$ cell receptor by physiological ligands delivers a stop signal to lymphocytes migrating on purified ligand ICAM-1 (Dustin et al., 1997). In these experiments, it was observed that the MTOC was repositioned to a location adjacent to the site of stable lymphocyte anchorage, suggesting that the MTOC in the arrested cells could have a role in maintaining the nonmotile phenotype of these cells. We observe in our immunofluorescence and video microscopy experiments that the MTOC in polarized lymphocytes is consistently found at a specific cytoplasmic location, in the region between the cell body and the long cellular extension, which is characterized by strong anchorage to the substrate ICAM-1. These results concur with two recent reports describing that the MTOC localizes to the distal portion of the posterior appendage known as uropod in polarized migrating lymphocytes (Ratner et al., 1997; Serrador et al., 1997). Furthermore, it has been reported that activation of human $\mathrm{T}$ lymphocytes induces tyrosine phosphorylation of $\alpha$-tubulin (Ley et al., 1994; Marie-Cardine et al., 1995). Interestingly, LFA-1-induced activation of PYK-2 was blocked by pretreatment of the cells with agents that interfere with actin and tubulin components of cytoskeleton, suggesting that PYK-2 activation requires cytoskeletal integrity to allow the activation of this enzyme. It is noteworthy that in other systems FAK and PYK-2 activation is blocked with agents that affect actin, but not tubulin, polymerization (Sinnett-Smith et al., 1993; Astier et al., 1997; Rodríguez-Fernández et al., 1998).

In conclusion, in this study we demonstrate that the interaction between activated integrin LFA-1 and its ligand ICAM-1 leads to changes in cell morphology and to the acquisition of a nonmotile phenotype of $\mathrm{T}$ lymphocytes. We show, for the first time, that concomitant with these changes, LFA- 1 induces activation of the cytoplasmic tyrosine kinases FAK and PYK-2 and redistribution of both kinases to a region close to the MTOC

\section{ACKNOWLEDGMENTS}

We greatly appreciate the generous supply of mAb KIM-127 provided by Dr. Martyn Robinson (Celltech, Slough, United Kingdom) and the generous gift of taxol provided by Dr. J.M. Andreu. We thank Tim Hutton, Peter Jordan, Alex Stokes, and Reiner Pepperkok (Confocal Microscopy and Digital Image Unit, Imperial Cancer Research Fund) for help with the video and confocal microscopy experiments, Reyes Tejedor for help with the preparation of recombinant ICAM-1-Fc, and Dr. Joaquín Teixidó for carefully reviewing the manuscript. This work was supported by Dirección General de Investigación Científica y Técnica Promoción General del Conocimiento grant PB94-0231 (to C.C.), Comunidad de Madrid Acciones Coordinadas en Ciencias de la Salud grants 07/044/96 (to C.C. and F.S.M.) and 08.1/0015/97 (to C.C.), a grant from Fundación Científica de la Asociación Española contra el Cáncer (to F.S.M. and C.C.) and Comisión Interministerial de Ciencia y Tecnología grants SAF 96/0039 (to F.S.M.) and SAF 98/0080 (to C.C.). C.C. was also partially supported by the European Molecular Biology Labo- ratory short-term fellowship ASTF8757. J.L.R.F. was supported by a Contrato de Reincorporación associated with grants PB94-0231 and SAF 98/0080, awarded by the Ministerio Español de Educación y Cultura. A.L. was supported by Comunidad de Madrid grant 07/ 044/96.

\section{REFERENCES}

Akasaka. T., van Leeuwen. R.L., Yoshinaga, I.G., Mihr, M.C., Jr., and Byers, H.R. (1995). Focal adhesion kinase (p125 $\left.{ }^{\mathrm{FAK}}\right)$ expression correlates with motility of human melanoma cell lines. J. Invest. Dermatol. 105, 104-108.

Akiyama, S.K., Yamada, S.S., Yamada, K.M., and LaFlamme, S.E. (1994). Transmembrane signal transduction by integrin cytoplasmic domain expressed in single-subunit chimeras. J. Biol. Chem. 269, 15961-15964.

Akiyama, T., Ishida, J., Nakagawa, S., Ogawara, H., Watanabe, S.-i., Itoh, N., Shibuya, M., and Fukami, Y. (1987). Genistein, a specific inhibitor of tyrosine-specific protein kinases. J. Biol. Chem. 262, 5592-5595.

Arroyo, A.G., Campanero, M.R., Sánchez-Mateos, P., Zapata, J.M., Ursa, M.A., del Pozo, M.A., and Sánchez-Madrid F. (1994). Induction of tyrosine phosphorylation during ICAM-1 and LFA-1 mediated intercellular adhesion and its regulation by CD45 tyrosine phosphatase. J. Cell Biol. 126, 1277-1286.

Astier, A., Avraham, H., Manié, S.N., Groopman, J., Canty, T., Avraham, S., and Freedman, A.S. (1997). The related focal adhesion tyrosine kinase (RAFTK) is tyrosine phosphorylated after $\beta 1$ integrin stimulation in B cells and binds to p130 ${ }^{\mathrm{CAS}}$. J. Biol. Chem. 272, $228-232$.

Avraham, S., et al. (1995). Identification and characterization of a novel related adhesion focal tyrosine kinase (RAFTK) from megakaryocytes and brain. J. Biol. Chem. 270, 27742-27751.

Berendt, A.R., McDowall, A., Craig, A.G., Bates, P.A., Stenberg, M.J.E., Marsh, K., Newbold, C.I., and Hogg, N. (1992). The binding site on ICAM-1 for Plasmodium falciparum-infected erythrocytes overlaps, but is distinct from, the LFA-1 binding site. Cell 68, 71-81.

Cary, L.A., Chang, J.F., and Guan, J.-L. (1996). Stimulation of cell migration by overexpression of focal adhesion kinase and its association with Src and Fyn. J. Cell Sci. 109, 1787-1794.

Clark, E.A., and Brugge, J.S. (1995). Integrins and signal transduction pathways: the road taken. Science 268, 233-139.

del Pozo, M.A., Cabañas, C., Montoya, M.C., Ager, A., SánchezMateos, P., and Sánchez-Madrid, F. (1997). ICAMS redistributed by chemokines to cellular uropods as a mechanism for recruitment of T lymphocytes. J. Cell Biol. 137, 493-508.

del Pozo, M.A., Sánchez-Mateos, P., and Sánchez-Madrid, F. (1996). Cellular polarization induced by chemokines: a mechanism for leukocyte recruitment?. Immunol. Today 17, 127-131.

Dikic, I., Tokiwa, G., Lev, S., Courtneidge, S.A., and Schlessinger, J. (1996). A role for Pyk2 and Src in linking G-protein-coupled receptors with MAP kinase activation. Nature 383, 547-550.

Dransfield, I., Cabañas, C., Barrett, J., and Hogg, N. (1992a). Interaction of leukocyte integrins with ligand is necessary but not sufficient for function. J. Cell Biol. 116, 1527-1535.

Dransfield, I., Cabañas, C., Craig, A., and Hogg, N. (1992b). Divalent cation regulation of the function of the leukocyte integrin LFA-1. J. Cell Biol. 116, 219-226.

Dustin, M.L., Bromley, S.K., Kam, Z., Peterson, D.A., and Unanue, E.R. (1997). Antigen receptor engagement delivers a stop signal to migrating T lymphocytes. Proc. Natl. Acad. Sci. USA 94, 3909-3913. 
Earp, H.S., Huckle, W.R., Dawson, T.L., Li, X., Graves, L.M., and Dy, R. (1995). Angiotensin II activates at least two tyrosine kinases in rat liver epithelial cells. J. Biol. Chem. 270, 28440-28447.

Ganju, R.K., Hatch, W.C., Avraham, H., Ona, M.A., Druker, B., Avraham, S., and Groopman, J. (1997). RAFTK, a novel member of the focal adhesion kinase family, is phosphorylated and associates with signaling molecules upon activation of mature $\mathrm{T}$ lymphocytes. J. Exp. Med. 185, 1055-1063.

Gates, R.E., King, L.E., Jr., Hanks, S.K., and Nanney, L.B. (1994). Potential role for adhesion kinase in migrating and proliferating keratinocytes near epidermal wounds and in culture. Cell Growth \& Differ. 5, 891-899.

Geiger, B., Rosen, D., and Berke, G. (1982). Spatial relationships of microtubule organizing center and the contact area of cytotoxic $\mathrm{T}$ lymphocytes and target cells. J. Cell Biol. 95, 137-143.

Gilmore, A.P., and Romer, L.H. (1996). Inhibition of focal adhesion kinase (FAK) signaling in focal adhesions decreases cell motility and proliferation. Mol. Biol. Cell 7, 1209-1224.

Gismondi. A., Bisogno, L., Mainiero, F., Palmeri, G., Piccoli, M., Frati, L., and Santoni, A. (1997). Proline-rich tyrosine kinase-2 activation by $\beta 1$ integrin fibronectin receptor cross-linking and association with paxillin in human natural killer cells. J. Immunol. 159, $4729-4736$.

Guan, J.-L., and Shalloway, D. (1992). Regulation of pp125 $5^{\text {FAK }}$ both by cellular adhesion and by oncogene transformation. Nature 358 , 690-692.

Hamawy, M.M., Mergenhagen, S.E., and Siraganian, R.P. (1993). Tyrosine phosphorylation of pp125 12 FAK by the aggregation of high affinity immunoglobulin E receptor requires cell adherence. J. Biol. Chem. 268, 6851-6854.

Hanks, S.K., Calalb, M.B., Harper, M.C., and Patel, S.K. (1992). Focal adhesion protein tyrosine kinase phosphorylated in response to cell spreading on fibronectin. Proc. Natl. Acad. Sci. USA 89, 8487-8491.

Hanks, S.K., and Polte, T.R. (1997). Signaling through focal adhesion kinase. Bioessays 19, 137-145.

Herzog, H., Nicholl, J., Hort, Y.J., Sutherland, G.R., and Shine, J. (1996). Molecular cloning and assignment of FAK2, a novel human focal adhesion kinase, to 8 p11.2-p22, by nonisotopic in situ hybridization. Genomics 32, 484-486.

Hiregowdara, D., Avraham, H., Fy, Y., London, R., and Avraham, S. (1997). Tyrosine phosphorylation of the related adhesion tyrosine kinase (RAFTK) in megakaryocytes upon stem cell factor and PMA stimulation and its association with paxillin. J. Biol. Chem. 272, 10804-10810.

Ilic, D., et al. (1995). Reduced cell motility and enhanced focal adhesion contact formation in cells from FAK-deficient mice. Nature $377,539-544$.

Kanner, S.B. (1996). Focal adhesion kinase-related fakB is regulated by the integrin LFA-1 and interacts with the SH3 domain of phospholipase C $\gamma 1$. Cell. Immunol. 171, 164-169.

Kanner, S.B., Aruffo, A., and Chan, P.-Y. (1994). Lymphocyte antigen receptor activation of a focal adhesion kinase-related tyrosine kinase substrate. Proc. Natl. Acad. Sci. USA 91, 10484-10487.

Kanner, S.B., Grosmaire, L.S., Ledbetter, J.A., and Damle, N.K. (1993). $\beta 2$ integrin LFA-1 signaling through phospholipase C- $\gamma-1$ activation. Proc. Natl. Acad. Sci. USA 90, 7099-7103.

Kornberg, L.J., Earp, H.S., Turner, C.E., Prockop, C., and Juliano, R.L. (1991). Signal transduction by integrins: increased protein phosphorylation caused by integrin clustering. Proc. Natl. Acad. Sci. USA $88,8392-8396$.
Kupfer, A., Mosmann, T.R., and Kupfer, H. (1991). Polarized expression of cytokines in cell conjugates of helper T cells and splenic B cells. Proc. Natl. Acad. Sci. USA 88, 775-779.

Lev, S., Moreno, H., Martinez, R., Canoll, P., Peles, E., Musacchio, J.M., Plowman, G.D., Rudy, B., and Schlessinger, J. (1995). Protein tyrosine kinase PYK2 involved in $\mathrm{Ca}^{2+}$-induced regulation of ion channel and MAP kinase functions. Nature 376, 737-745.

Ley, S.C., Verbi, W., Pappin, D.J., Druker, B., Davies, A.A., and Crumpton, M.J. (1994). Tyrosine phosphorylation of alpha tubulin in human T lymphocytes. Eur. J. Immunol. 24, 99-106.

Li, J., Avraham, H., Rogers, R.A., Raja, S., and Avraham, S. (1996). Characterization of RAFTK, a novel focal adhesion kinase, and its integrin-dependent phosphorylation and activation in megakaryocytes. Blood 88, 417-428.

Lipfert, L., Haimovitch, B., Schaller, M.D., Cob, B.S., Parsons, J.T., and Brugge, J.S. (1992). Integrin dependent phosphorylation and activation of the protein tyrosine kinase $\mathrm{pp} 125^{\mathrm{FAK}}$ in platelets. J. Cell Biol. 119, 905-912.

Lowin-Kropf, B., Shapiro, V.S., and Weiss, A. (1998). Cytoskeletal polarization of $\mathrm{T}$ cells is regulated by an immunoreceptor tyrosinebased activation motif-dependent mechanism. J. Cell Biol. 140, 861871.

Lub, M., van Kooyk, Y., and Figdor, C.G. (1995). Ins and outs of LFA-1. Immunol. Today 16, 479-483.

Luque, A., Gómez, M., Puzon, W., Takada, Y., Sánchez-Madrid, F., and Cabañas, C. (1996). Activated conformations of VLA integrins detected by a group of antibodies (HUTS) specific for a novel regulatory region (355-425) of the common $\beta 1$ chain. J. Biol. Chem. $271,11067-11075$

Ma, E.A., Lou, O., Berg, N.N., and Ostergaard, H.L. (1997). Cytotoxic $\mathrm{T}$ lymphocytes express a $\beta 3$ integrin which can induce the phosphorylation of focal adhesion kinase and the related PYK-2. Eur. J. Immunol. 27, 329-335.

Maguire, J.E., Danahey, K.M., Burkly, L.C., and van Seventer, G.A. (1995). T cell receptor and beta-1 integrin-mediated signals sinergize to induce tyrosine phosphorylation of focal adhesion kinase (pp125 ${ }^{\mathrm{FAK}}$ ) in human T cells. J. Exp. Med. 182, 2079-2090.

Marie-Cardine, A., Kirchgessner, H., Eckerskorn, C., Meuer, S.C., and Schraven, B. (1995). Human T lymphocyte activation induces tyrosine phosphorylation of alpha tubulin and its association with the $\mathrm{SH} 2$ domain of the p59fyn protein tyrosine kinase. Eur. J. Immunol. 25, 3290-3297.

Matsumoto, K., Matsumoto, K., Nakamura, T., and Kramer, R.H. (1994). Hepatocyte growth factor induces tyrosine phosphorylation of focal adhesion kinase ( $\mathrm{pp} 125^{\mathrm{FAK}}$ ) and promotes migration and invasion by oral squamous cell carcinoma cells. J. Biol. Chem. 269, 31807-31813.

Ohba, T., Ishino, M., Aoto, H., and Sasaki, T. (1998). Interaction of two proline-rich sequences of cell adhesion kinase $\beta$ with $\mathrm{SH} 3$ domains of $\mathrm{p} 130^{\mathrm{CAS}}$ related proteins and GTPase-activating protein, graf. Biochem. J. 330, 1249-1254.

Ortlepp, S., Stephens, P.E., Hogg, N., Figdor, C.C., and Robinson, M.K. (1995). Antibodies that activate $\beta 2$ integrins can generate different ligand binding states signals. Eur. J. Immunol. 25, 637-643.

Otey, C.A. (1996). pp $125^{\mathrm{FAK}}$ in the focal adhesion. Int. Rev. Cytol. 167, 161-183.

Raja, S., Avraham, S., and Avraham, H. (1997). Tyrosine phosphorylation of the novel protein tyrosine kinase RAFTK during an early phase of platelet activation by an integrin glycoprotein gpIIb-IIIaindependent mechanism. J. Biol. Chem. 272, 10941-10947. 
Ratner, S., Sherrod, W.S., and Lichlyter, D. (1997). Microtubule retraction into the uropod and its role in $\mathrm{T}$ cell polarization and motility. J. Immunol. 159, 1063-1067.

Richardson, A., and Parsons, T. (1995). Signal transduction through integrins: a central role for focal adhesion kinase? Bioessays 17, 229-236.

Richardson, A., and Parsons, T. (1996). A mechanism for regulation of the adhesion-associated protein tyrosine kinase $\mathrm{pp} 125^{\mathrm{FAK}}$. Nature 380, 538-540.

Rodríguez-Fernández, J.L., Geiger, B., Salomon, D., Sabanay, I., Zöller, M., and Ben-Ze'ev, A. (1992). Suppression of tumorigenicity in transformed cells transfected with vinculin cDNA. J. Cell Biol. 119, 427-438.

Rodríguez-Fernández, J.L., and Rozengurt, E. (1996). Bombesin, bradykinin, vasopressin, and phorbol esters rapidly and transiently activate Src family tyrosine kinases in Swiss 3T3 cells. J. Biol. Chem. 271, 27895-27901.

Rodríguez-Fernández, J.L., and Rozengurt, E. (1998). Bombesin, vasopressin, lysophosphatidic acid and sphingosylphosphorylcholine stimulate focal adhesion kinase activity in intact Swiss 3T3 cells. J. Biol. Chem. 273, 19321-19328.

Rothlein, R., and Springer, T.A. (1986). The requirement for LFA-1 in homotypic leukocyte adhesion stimulated by phorbol ester. J. Exp. Med. 163, 1132-1149.

Sánchez-Madrid, F., and del Pozo, M.A. (1999). Leukocyte polarization in cell migration and immune interactions. EMBO J. 18, 501511.

Sasaki, H., Nagura, K., Ishino, M., Tobioka, H., Kotani, K., and Sasaki, T. (1995). Cloning and characterization of cell adhesion kinase $\beta$, a novel protein-tyrosine kinase of the focal adhesion kinase subfamily. J. Biol. Chem. 270, 21206-21219.

Schaller, M.D., Borgman, C.A., Cobbs, B.S., Vines, R.R., Reynols, A.B., and Parsons, J.T. (1992). pp $125^{\mathrm{FAK}}$, a structurally unique protein kinase associated with focal adhesions. Proc. Natl. Acad. Sci. USA 89, 5192-5196.

Schaller, M.D., Borgman, C.A., and Parsons, J.T. (1993). Autonomous expression of a noncatalytic domain of the focal adhesionassociated protein tyrosine kinase pp125 $5^{\mathrm{FAK}}$. Mol. Cell. Biol. 13, 785-791.

Schaller, M.D., Otey, C.A., Hildebrand, J.D., and Parsons, J.T. (1995). Focal adhesion kinase and paxillin bind to peptides mimicking $\beta$ integrin cytoplasmic domain. J. Cell Biol. 130, 1181-1187.

Schlaepfer, D.D., Jones, K.C., and Hunter, T. (1998). Multiple Grb2-mediated integrin stimulated signaling pathways to ERK-2/mitogen-activated protein kinase: summation of both c-src- and focal adhesion kinase-initiated tyrosine phophorylation events. Mol. Cell. Biol. 18, 2571-2585.
Schwartz, M.A., Schaller, M.D., and Gingsberg, M.H. (1995). Integrins: emerging paradigms of signal transduction. Annu. Rev. Cell. Dev. Biol. 11, 549-599.

Serrador, J., Alonso-Lebrero, J.L., del Pozo, M.A., Furthmayr, H., Schwartz-Albiez, R., Calvo, J., Lozano, F., and Sánchez-Madrid, F. (1997). Moesin interacts with the cytoplasmic region of intercellular adhesion molecule- 3 and is redistributed to the uropod of T lymphocytes during cell polarization. J. Cell Biol. 138, 1409-1423.

Shattil, S.J., Haimovitch, B., Cunningham, M., Lipfert, L., Parsons, J.T., Ginsberg, M.H., and Brugge, J. (1994). Tyrosine phosphorylation of pp $125^{\mathrm{FAK}}$ requires coordinated signaling through integrin and agonist receptors. J. Biol. Chem. 269, 14738-14745.

Singer, S.J. (1992). Intercellular communication and cell-cell adhesion. Science 255, 1671-1677.

Sinnett-Smith, J., Zachary, I., Valverde, A.M., and Rozengurt, E. (1993). Bombesin stimulation of p125 focal adhesion kinase tyrosine phosphorylation. Role of protein kinase $\mathrm{C}_{1} \mathrm{Ca}^{2+}$ mobilization, and the actin cytoskeleton. J. Biol. Chem. 268, 14261-14268.

Springer, T.A. (1990). Adhesion receptors in the immune system. Nature 346, 425-434

Stephens, P., Romer, J.T., Shock, A., Ortlepp, S., Figdor, C., and Robinson, M.K. (1995). KIM-127, an antibody that promotes adhesion, maps to a region of CD18 that includes cystein-rich repeats. Cell Adhes. Commun. 3, 375-384.

Stewart, M.P., Cabañas, C., and Hogg, N. (1996). T cell adhesion to intercercellular adhesion molecule-1 (ICAM-1) is controlled by spreading and by activation of integrin LFA-1. J. Immunol. 156, 1810-1817.

van Kooyk, Y., Weder, P., Hogervorst, F., Verhoeven, A.J., van Seventer, G., te Velde, A.A., Borst, J., Keizer, C.G., and Figdor, C.G. (1991). Activation of LFA-1 through $\mathrm{Ca}^{2+}$-dependent epitope stimulates lymphocyte adhesion. J. Cell Biol. 112, 345-354.

Wacholtz, M.C., Patel, S.S., and Lipsky, P.E. (1989). Leukocyte function-associated antigen 1 is an activation molecule for human $\mathrm{T}$ cells. J. Exp. Med. 170, 431-448.

Wilkinson, P.C., and Higgins, A. (1987). OKT3-activated locomotion of human blood lymphocytes: a phenomenon requiring contact of $\mathrm{T}$ cells with Fc receptor-bearing cells. Immunology 60, 445-451.

Xiong, W.-C., and Parsons, J.T. (1997). Induction of apoptosis after expression of PYK2, a tyrosine kinase structurally related to focal adhesion kinase. J. Cell Biol. 139, 529-539.

Yu, H., et al. (1996). Activation of a novel $\mathrm{Ca}^{2+}$-dependent protein tyrosine kinase. Correlation with c-jun N-terminal kinase but not mitogen-activated protein kinase activation. J. Biol. Chem. 271, 29993-29998.

Zheng, C., Zheng, X., Bian, Z.C., Guo, C., Akbay, A., Warner, L., and Guan, J.-L. (1998). Differential regulation of Pyk2 and focal adhesion kinase (FAK). J. Biol. Chem. 273, 2384-2389. 